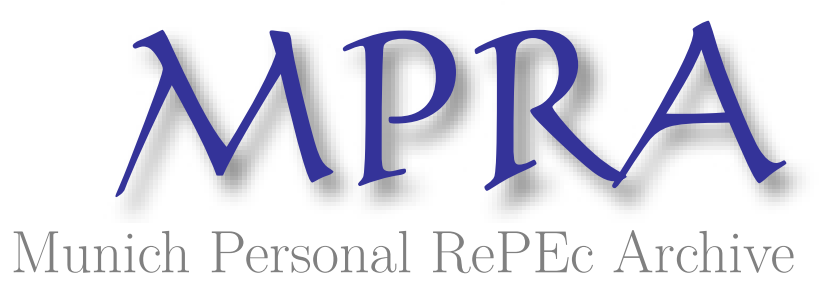

\title{
Credit Constraints in Higher Education in a Context of Unobserved Heterogeneity
}

Villena, Mauricio and Sanchez, Rafael and Rojas, Eugenio

Universidad Adolfo Ibáñez, Universidad Adolfo Ibáñez, University of Pennsylvania

23 April 2012

Online at https://mpra.ub.uni-muenchen.de/62095/

MPRA Paper No. 62095, posted 28 Feb 2015 08:55 UTC 


\title{
Credit Constraints in Higher Education in a Context of Unobserved Heterogeneity*
}

\author{
Eugenio Rojas \\ University of Pennsylvania
}

\author{
Rafael Sánchez \\ Adolfo Ibáñez University
}

First Version: April 23, 2012

This Version: July 8, 2014

\author{
Mauricio G. Villena \\ Adolfo Ibáñez University
}

\begin{abstract}
This article tests the existence of credit constraints on higher education access by estimating actual marginal returns in the context of unobserved heterogeneity. We estimate higher education returns for those who attend to it and compare them with those of individuals who are at the margin of attending to it. Following the Carneiro and Heckman (2002) reasoning, if the returns of the latter group are larger than those of the former one we could be in presence of unobservable barriers to higher education access, such as credit constraints. We use a rich administrative database composed from three sources: data of enrollment and graduation from the Chilean higher education system, test scores and labor market outcomes from the Chilean Unemployment Insurance database. Our results suggest that, given the existing financial aid scheme, the returns for those individuals that are at the margin of attending to higher education are lower than for those who decided to attend to it. This is, no evidence of credit constraints is found for the Chilean Higher Education system. However, when conditioning on family income, we find that for the richer households some evidence of credit constraints is found.
\end{abstract}

Keywords: Higher Education, Credit Constraints, Structural Models, Marginal Treatment Effect JEL Classification: C35, I23, I25, J31

${ }^{*}$ We thank the Chilean Budget Office for providing us access to the data. The data analysis was carried out in a secure server. We also thank Alejandro Pérez-Cotapos for outstanding research assistance. 


\section{Introduction}

The promotion of higher education access, specially for those individuals with most limited economic resources, has turned to be a priority in the public policy debate of several countries, no matter the political spectrum. A common method for tackling this concern is by expanding the coverage of grants and student loans. This expansion is grounded on the assumption that a fraction of the population faces credit constraints for financing their higher education studies, which may lead to human capital under investment and hence to lower private and social returns. Nevertheless, these benefits associated with lower credit constraints come at a cost, the large fiscal burden of these policies and the alternative costs of resources that may be allocated to individuals that may have access to private resources. Thus, these are elements that the authority must be cautious with when expanding the coverage of benefits, specially in a context of limited fiscal resources. An indiscriminate growth of benefits, in a context without credit constraints, carries significant opportunity costs because those resources may be destined to alternative public policies with larger social returns.

In this context, the identification of credit constraints is an important challenge for public policy. Several approaches for testing the existence of credit constraints in higher education have been considered in the literature, as it is very difficult to identify credit constrained individuals (Kane, 1996). On the one hand, there are articles focused on assessing the effect that financial aid has on enrollment (Kane, 1996, 2007; Cameron and Heckman, 2001; Lochner and Monge-Naranjo 2011; Rau , Rojas and Urzúa, 2013). On the other hand, we find studies that consider the economic returns of higher education (Carneiro and Heckman, 2002; Cameron and Taber, 2004; Kaufmann, 2012). The first group analyzes if the access to financial aid positively affects higher education enrollment, a result that may shed light on the existence of credit constraints. The second group is focused on higher education returns and with them it is assessed whether individuals who decided not to attend higher education would have obtained larger returns than those who decided to attend.

Regarding the first group, Kane (1996) suggests the existence of credit constraints on the U.S. higher education access by analyzing tuition costs: in those states with higher tuition costs there is greater delay in enrolling in higher education institutions. This can be understood as a previous saving process in order to be able to fund higher education studies. Lochner and Monge-Naranjo (2011) conclude similar results via simulations, where positive effects on enrollment are found when relaxing financial requirements of higher education access.

Articles focusing on economic returns such as Cameron and Heckman (2001), Cameron and Taber (2004) 
and Kaufmann (2012), find no evidence of credit constraints on higher education access in United States and Mexico. The first two articles suggest that ability constraints (or long run constraints) rather than credit constraints (or short run constraints) are the main determinants behind the decision of attending to a higher education institution. Kaufmann (2012) uses a survey of economic returns that individuals expect to have in the future in order to identify the existence of credit constraints in Mexico, concluding that those who are at the margin of attending or not to a higher education institution would have larger economic returns than those who are attending, implying the presence of credit constraints.

Our article is based on the methodology proposed in Carneiro, Heckman and Vytlacil (2011) for estimating marginal returns of higher education, and contributes to the existing literature by considering unobserved heterogeneity and rich administrative data. This is important since previous reported evidence utilizes methods such OLS and instrumental variables, which may conduct to misleading conclusions or results which heavily depend upon the considered instrument (Heckman, Urzúa and Vytlacil, 2006). ${ }^{1}$

Unlike previous studies, this paper tests the existence of credit constraints in higher education access by comparing the actual economic returns of individuals who attended to it with those of who are at the margin of attending to it, in the context of unobserved heterogeneity models (Willis and Rosen, 1979; Card, 1994, 1995; Taber, 2001, Heckman and Vytlacil, 2005; Heckman, Urzúa and Vytlacil, 2006; Carneiro, Heckman and Vytlacil, 2010, 2011; Kaufmann, 2012). In order to identify individuals, and following Carneiro, Heckman and Vytlacil (2011), our empirical strategy consists in simulating marginal changes in different policies so we can identify who are at the margin of attending or not to a higher education institution. Thus, by using the Marginal Treatment Effect methodology (MTE, see more details in Heckman and Vytlacil, 1999, 2005; Heckman, Urzúa and Vytlacil, 2006) we estimate the economic returns of this group and then compare it with the estimated returns of those who attend a higher education institution.

The intuition behind our empirical strategy follows the idea posed in Carneiro and Heckman (2002). If individuals that are at the margin of attending (or not) a higher education institution obtain larger economic returns than those of individuals who attend a higher education institution, then the formers are facing an unobservable barrier (for the econometrician) in the access to higher education, such as credit constraints. This approach is directly related to what is presented in articles such as Becker (1967), Willis and Rosen (1979) and Card (1994), in which these constraints are modeled as self-specific interest rates (individuals who face greater interest rates will have more difficulties obtaining resources to finance their higher education studies).

\footnotetext{
${ }^{1}$ To be more precise, different groups will be induced to attend to a higher education institution depending on the considered instrument. These groups will not necessarily be the same. Clearly this introduces problems in the adequate identification of the relevant treatment effects.
} 
The specific application presented in this work is the Chilean case, for which we use a rich administrative database composed of three sources: data of enrollment and graduation from the Chilean higher education system, test scores and labor market outcomes from the Chilean Unemployment Insurance database. Our results show that individuals with lower unobservable costs of attending a higher education institution obtain greater economic returns. When considering more flexible function forms we are unable to reject the hypothesis of null (or even negative) economic returns for individuals with high unobservable costs of attending higher education. Furthermore, our results show that, given the current financial aid scheme of grants and credits, the returns of those who are at the margin of attending or not a higher education institution are lower than of those who decided to attend. This result holds even when considering different policy changes and different functional forms. Nevertheless, when conditioning on different family income levels, we find some evidence of credit constraints for higher income families. It is important to notice that our analysis is performed for cohorts who started to study in 2006, when a massive program of student loans was starting (the State Guaranteed Loan, see Rau, Rojas and Urzúa, 2013, for further details) and before the large increase in the number of grants for higher education, which started in 2011.

This paper is organized as follows. Section 2 describes the Institutional background of the Chilean Higher Education System Section 3 describes the proposed model to be estimated, along with the corresponding assumptions. Section 4 describes the datasets and presents descriptive statistics of our sample. Section 5 shows the practical issues that arise when estimating the type of models that we use and Section 6 presents the basic results of our estimation. Finally, Section 7 put forward some concluding remarks.

\section{The Case of the Chilean Higher Education System: Institutional Background}

In Chile once graduated from high school, individuals are able to choose between entering the labor market or attending to a higher education institution. In case they decide the second alternative, individuals must take national standarized test, the University Selection Test (Prueba de Selección Universitaria, PSU). ${ }^{2}$ This test is required by most higher education institutions in Chile. According to the Chilean Ministry of Education, nearly $96 \%$ of the high school graduates take this test and hence it seems reasonable to consider individuals who have taken it in our sample.

\footnotetext{
${ }^{2}$ The University Selection Test assesses the students' skills once they graduate from high school. This test considers two mandatory sections (Mathematics and Language) and two optional sections (Sciences and History), of which the student must take at least one of them. The scores range from 150 to 850 points.
} 
Higher education institutions are divided into three groups: Universities, Professional Institutes and Technical Institutes. The main difference between these institutions relies on the offered certification level. Universities grant bachelor, professional and graduate degrees, Professional Institutes are able to grant technical and professional degrees, and Technical Institutes grant technical degrees. Table 1 presents the total undergraduate enrollment by type of higher education institution. We see that an important fraction of total undergraduate enrollment, $62 \%$, is focused in Universities, followed by Professional and Technical Institutes, with $25 \%$ and $13 \%$ of the total enrollment, respectively.

Although higher education access was quite uneven for several groups (Espinoza et al., 2006), in the last years this trend has changed due to the increase in the number of student aids (grants and loans) for the most vulnerable sectors, especially after the implementation of the Chilean State Guaranteed Loan in year 2006. Most of the financial aid are conditional on a minimum PSU score (generally over 475 points in the Math and Language tests, or at least a 5.3 GPA (out of 7.0) in high school in the case of Professional or Technical Institutes) and income levels. ${ }^{3}$ Table 2 shows the main grants and loans available in 2006, with a description and requirements in order to be eligible.

The increase in the number of financial aids has had a positive effect in higher education enrollment, as Figures 1 and 2 present. Tables 3, 4 and 5 show that there has been a substantial growth in the coverage of financial aids for lower income sectors. It is important to notice that, as detailed below, our analysis considers the cohort that enrolled in higher education institutions in 2006 and hence students face a different context of grants and loans (which is before the large increase in the number of financial aids).

What is stated above raises the following question: were credit constraints present in higher education access in the Chilean context?. This paper assesses this question for the period right before the large increase in financial aids. If the answer would have been "no", then the important increment in credits and scholarships from 2006-2012 would had been allocated to individuals without credit constraints with the subsequent opportunity cost of fiscal resources. Alternatively, if no credit constraints in higher education access are found, then economic resources may have been handed over to individuals whose optimal decision may have been not to attend a higher education institution. ${ }^{4}$ In the case that credit constraints were present in the higher education system, more resources focused on the most needed sectors would have been justified.

\footnotetext{
${ }^{3}$ The Chilean grade scale ranges from 1.0 to 7.0 , where 4.0 is the minimum passing grade.

${ }^{4}$ Reyes, Rodríguez and Urzúa (2013) finds evidence in Chile of negative returns to higher education for a certain group of individuals.
} 


\section{Estimating Marginal Returns to Higher Education under Un- observed Heterogeneity}

In order to test for the existence of credit constraints in higher education access we consider a generalized Roy model (Roy, 1951), following Heckman and Vytlacil (1999, 2005), Heckman, Urzúa and Vytlacil (2006) and Carneiro, Heckman and Vytlacil (2011). Assume two possible higher education scenarios. In the first one individuals that graduate from high school take a national standardized university admissions test and do not enroll in a higher education institution. In the second scenario we have the same individuals but who finally enrolle in a higher education institution and graduate from it. ${ }^{5}$ The equations that determine the level of wages in this context are the following:

$$
\begin{aligned}
& W_{1}=\mu_{1}(X)+U_{1} \\
& W_{0}=\mu_{0}(X)+U_{0}
\end{aligned}
$$

Where $W_{1}$ and $W_{0}$ are the wages that individuals who attended, and did not, to a higher education institution perceive, respectively, $\mu_{1}(X)$ is a function that determines wages for those who decided to attend higher education, $X$ is a vector of observable characteristics that affect wages and $\mu_{0}(X)$ is a function that determines wages for those individuals who did not attend higher education. Finally, $U_{1}$ and $U_{0}$ are error components that affect wages of the individuals who pursued, and did not, not higher education, respectively. Thus, the higher education return will be given by $R=E\left(W_{1}-W_{0} \mid X\right)=\mu_{1}(X)-\mu_{0}(X)+E\left(U_{1}-U_{0} \mid X\right)$. In order to be able to model this return we must analyze the part of the equation that depends on the selection of individuals $\left(E\left(U_{1}-U_{0} \mid X\right) \neq 0\right)$. We assume that the decision of attending or not to higher education is modeled by the following rule:

$$
A=\left\{\begin{array}{lll}
1 & \text { if } & A^{*}>0 \\
0 & \text { if } & A^{*} \leq 0
\end{array}\right.
$$

Where the decision of attending, $A$, is equal to 1 if the individual attends to a higher education institution and 0 if this is not the case (i.e. to attend and graduate from higher education will be our treatment). Thus, we have that $W=A \cdot W_{1}+(1-A) \cdot W_{0}$. The decision variable depends upon a latent variable, $A^{*}$, which determines the utility level that the individual will perceive in both scenarios. We model this latent utility

\footnotetext{
${ }^{5}$ We exclude from our analysis those who enrolled in a higher education institution and later dropped out and those who do not take the PSU test.
} 
as follows:

$$
A^{*}=\gamma Z-V
$$

Where $Z$ is a vector of observable variables that affect the decision of attending (and graduating) to a higher education institution or not, $\gamma$ is a parameter that measures how relevant are the previously mentioned variables on the studied choice and $V$ is an unobservable component. Vector $Z$ contains instruments that affect the decision of attending (or not) to a higher education institution, and that are excluded from the wage equations. It is important to emphasize that in order to identify the treatment parameter the assumption $Z \mid X \perp U_{1}, U_{0}, V$ must be met. The instruments that we consider would meet this condition, as we will detail below.

Thus, following Heckman, Urzúa and Vytlacil (2006) it is possible to define the probability of being treated (propensity score) as:

$$
\operatorname{Pr}(A=1, Z)=\operatorname{Pr}\left(\frac{V}{\sigma_{V}^{2}}<\frac{\gamma Z}{\sigma_{V}^{2}}\right)=\Phi\left(\frac{\gamma Z}{\sigma_{V}^{2}}\right)=P(Z)
$$

In order to identify the treatment effect for those individuals who are at the margin of being treated or not, we must estimate the effect that the treatment would have on wages for different margins (i.e. for different levels of propensity scores). In this sense, articles such as Heckman and Vytlacil (1999, 2005), Heckman, Urzúa and Vytlacil (2006) and Carneiro, Heckman and Vytlacil (2011) suggest to estimate the Marginal Treatment Effect (MTE), which depends on the probability of being treated. The propensity score, as detailed in Heckman, Urzúa and Vytlacil (2006), is very important in the context of instrumental variables since it satisfies the independence and monotonicity conditions of Imbens and Angrist (1994).

It is important to redefine the choice equation in terms of observables and unobservables:

$$
A=\left\{\begin{array}{lll}
1 & \text { if } & P(Z)-U_{A}>0 \\
0 & \text { if } & P(Z)-U_{A} \leq 0
\end{array}\right.
$$

Where $U_{A}=\Phi\left(\frac{V}{\sigma_{V}^{2}}\right)$. Thus, we can define the MTE as:

$$
\operatorname{MTE}\left(X=x, U_{A}=u_{A}\right)=E\left(R \mid X=x, U_{A}=u_{A}\right)
$$

We see that the MTE will take different values depending on the levels of unobservable $U_{A}$, that can be interpreted as the desire of attending to higher education (Carneiro, Heckman and Vytlacil, 2011). It is 
important to note the fact that individuals with greater values of $U_{A}$ are those that have lower probabilities of being treated. Thus, given that our analysis is based on the support of $U_{A}$, we can identify the individuals that would be induced to attend a higher education institution when marginal changes in the propensity score are made.

\subsection{Normal Specification}

For the wage equations different structures can be assumed, some of which are more restrictive than the others. Firstly, we start with the more restrictive parametric case for which it is possible to assume the structure of a normal model as specified below:

$$
\begin{aligned}
& W_{1}=\alpha_{1}+\varphi+X \beta_{1}+U_{1} \\
& W_{0}=\alpha_{0}+X \beta_{0}+U_{0}
\end{aligned}
$$

We assume that the unobserved components are not independent between them, even when conditioning on observables ( $U_{1} \perp U_{0} \perp V \mid X$ does not occur). We assume that the unobserved components follow a trivariate normal distribution:

$$
\left(U_{1}, U_{0}, V\right) \sim N(\mathbf{0}, \Sigma)
$$

Where $\Sigma$ is the covariance matrix of the error components. We define the variance of the error component $U_{i}$ as $\sigma_{i}^{2}$ (for $i=1,2$ ) and for component $V$ as $\sigma_{V}^{2}$. On the other hand, the covariance between component $U_{i}$ and component $V$ is given by $\sigma_{i, V}$ (for $i=1,2$ ) and for components $U_{i}$ and $U_{j}$ by $\sigma_{i, j}^{2}$. According to this specification, the definition of the MTE can be rewritten as:

$$
E\left(R \mid X=x, U_{A}=u_{A}\right)=\alpha_{1}+\varphi-\alpha_{0}+x\left(\beta_{1}-\beta_{0}\right)+\left(\rho_{1}-\rho_{0}\right) \Phi^{-1}\left(u_{A}\right)
$$

Where $\rho_{1}=\frac{\sigma_{1, V}}{\sigma_{V}^{2}}$ and $\rho_{0}=\frac{\sigma_{0, V}}{\sigma_{V}^{2}}$. We consider that $\frac{\gamma Z}{\sigma_{V}^{2}}=\Phi^{-1}(P(Z))$, that $E\left(W_{1} \mid A=1, X, Z\right)=$ $\alpha_{1}+\varphi+X \beta_{1}+\rho_{1} \cdot\left(-\frac{\phi\left(\Phi^{-1}(P(Z))\right)}{P(Z)}\right)$ and $E\left(W_{0} \mid A=0, X, Z\right)=\alpha_{0}+X \beta_{0}+\rho_{0} \cdot \frac{\phi\left(\Phi^{-1}(P(Z))\right)}{1-P(Z)} \cdot{ }^{6}$ Heckman, Urzúa and Vytlacil (2006) suggest two stages in order to estimate the MTE in the normal model context: (1) Estimate the propensity score through a probit estimation and then construct the predicted probabilities for each individual and (2) replace these probabilities in the MTE equation and estimate it by OLS.

\footnotetext{
${ }^{6}$ See Heckman and Vytlacil (1999, 2005) y Heckman, Urzúa and Vytlacil (2006) for more details.
} 


\subsection{Semiparametric Specification}

A second specification considers a less restrictive structure. Following Heckman, Urzúa and Vytlacil (2006), this structure is given by:

$$
E(W \mid X=x, P(Z)=p)=x \beta_{0}+\left(x\left(\beta_{1}-\beta_{0}\right)\right) p+K(p)
$$

Where $K(p)$ is a control function, in the sense of Heckman and Robb (1985) and $K(p)=E\left(U_{1}-U_{0} \mid A=\right.$ 1, $P(Z)=p)$. For this structure, the MTE will be given by the following equation:

$$
\operatorname{MTE}\left(X=x, U_{A}=p\right)=\frac{\partial E(W \mid X=x, P(Z)=p)}{\partial p}=x\left(\beta_{1}-\beta_{0}\right)+\frac{\partial K(p)}{\partial p}
$$

It is possible to semiparametrically estimate the previous expression in two stages (Heckman, Urzúa and Vytlacil, 2006; Carneiro, Heckman and Vytlacil, 2011). In a first stage we can assume that the function $K(p)$ is a polynomial of degree $k$ of the propensity score. ${ }^{7}$ By using the estimated parameters in the first stage we can now parametrically estimate $K(p)$. For this we run a local quadratic regression of $\widetilde{W}=$ $W-x \widehat{\beta_{0}}+\left(x\left(\widehat{\beta_{1}-\beta_{0}}\right)\right) \widehat{p}$ on $\widehat{p}$, with what is possible to obtain the level and the derivatives of $K(p)$, using the approach proposed in Heckman, Ichimura, Smith and Todd (1998). ${ }^{8}$ This assumes that $\widetilde{W}=K(p)+v$. With the estimated parameters it is possible to construct the MTE.

\subsection{Identification of the Relevant Economic Returns}

In order to test for the existence of credit constraints in higher education access we must estimate the returns of those who attended and graduated from it (the treated group) and of those who are at the margin of being treated or not. The answer for the latter group is not trivial. A priori it is not possible to define the group of individuals that are at the margin. For this, it is necessary to simulate a policy change (for example, reducing average tuition costs, increasing the number of higher education institutions or the average hourly wage for high school graduates, among other changes) in order to assess which individuals would be induced to receive or not the treatment.

Heckman and Vytlacil (2001) define the Policy Relevant Treatment Effect (PRTE) as a function of the

\footnotetext{
${ }^{7}$ We consider a degree 4 polynomial (i.e. $k=4$ ). As a robustness check we also considered degree 3 and 5 polynomials. The results that we obtain appear to be robust to the degree of the polynomial.

${ }^{8}$ Following Carneiro, Heckman y Vytlacil (2011), we consider 26 equally spaced points in the common support of the propensity score (from 0.002 to 0.929 ), in order to run a local quadratic regression (we use a gaussian kernel). For the optimal bandwidth selection we follow the Residual Squares criterion, proposed in Fan and Gijbels (1996). The optimal bandwidth is 0.1348 .
} 
MTE: ${ }^{9}$

$$
P R T E=\frac{E\left(W^{*}\right)-E(W)}{E\left(A^{*}\right)-E(A)}=\int_{0}^{1} M T E\left(u_{A}\right) \omega_{\mathrm{PRTE}}\left(u_{A}\right) d u_{A}
$$

Where $\omega_{\mathrm{PRTE}}\left(u_{A}\right)=\frac{F_{P}\left(u_{A}\right)-F_{P^{*}}\left(u_{A}\right)}{E_{F_{P^{*}}}(P)-E_{F_{P}}(P)}$ is the weight that is given to the MTE, which depends on the policy change. In this case $E\left(W^{*}\right)$ is the expected wage of an individual once the policy change is made, $E(W)$ is the expected wage under the base policy, $E\left(A^{*}\right)$ is the average probability of being treated in the new scenario and $E(A)$ is the probability of being treated on the base scenario. $F_{P^{*}}$ and $F_{P}$ are the cumulative distribution functions of the probability of being treated, with and without the policy change, respectively, while $E_{F_{P^{*}}}(P)$ is the expected value of the probability of being treated under the new scenario, which is equivalent in the case of the base scenario.

By using the parameters of the structural model we calculate the Treatment on the Treated (TT), which is equivalent to the economic return that the treated obtained. Following Heckman and Vytlacil (2005), the TT can be defined as a function of the MTE and is specified by the following equation:

$$
T T=\int_{0}^{1} M T E\left(u_{A}\right) \omega_{\mathrm{TT}}\left(u_{A}\right) d u_{A}
$$

Where $\omega_{\mathrm{TT}}\left(u_{A}\right)=\frac{\int_{u_{A}}^{1} f(a) d a}{E(A)}, f(a)$ is the probability density of being treated and $E(A)$ is the expected probability of being treated. Since we do not have a full common support for the propensity score, it is not possible to identify the TT according to the semiparametric model. However, we follow Carneiro, Heckman and Vytlacil (2011) and estimate it by re-calibrating the weights, so they add up to 1 in the support that we will work in.

Regarding the estimation of the conditional probability density function, which is necessary for the construction of the weights, it is important to notice the following. The multidimensionality of $X$ introduces a problem at the moment of estimating the conditional density of the propensity score. Given this, following Carneiro, Heckman and Vytlacil $(2010,2011)$, we condition on an index $X\left(\widehat{\beta_{1}-\beta_{0}}\right)$ instead of conditioning on $X .^{10}$

\footnotetext{
${ }^{9}$ We supress the conditioning on $X$ for the sake of simplicity.

${ }^{10}$ In the estimation of the conditional density function $f(P \mid X)$ we folow Carneiro, Heckman and Vytlacil (2010). We estimate a local linear regression of $\frac{1}{h} K\left(\frac{\widehat{p}-p}{h}\right)$ on the index $X\left(\widehat{\beta_{1}-\beta_{0}}\right)$, where $K(\cdot)$ is a gaussian kernel and $h=1.06 \cdot(\widehat{\operatorname{Var}}(P))^{1 / 2} \cdot n^{-1 / 5}$. For the local linear regression we consider a bandwidth equal to $h=1.06 \cdot\left(\widehat{\operatorname{Var}}\left(X\left(\beta_{1}-\beta_{0}\right)\right)\right)^{1 / 2} \cdot n^{-1 / 5}$.
} 
With these two parameters it is possible to test if the PRTE is greater than the TT. If this is the case, then this could be an indication of the presence of credit constraints.

It is important to note that, as Carneiro, Heckman and Vytlacil (2010) shows, in those cases in which a full support for the propensity score is not reached, it is not possible to identify the PRTE. Instead, the Marginal Policy Relevant Treatment Effect (MPRTE) is proposed. The MPRTE allows to identify the effects of marginal changes in policies despite not having a full common support. This is also an important difference of the approach followed in this work with that pursued in previous articles applied to similar contexts, such as Kaufmann (2012) that use the PRTE even when a full common support is not present.

The MPRTE assumes marginal changes in policies and is defined as follows:

$$
M P R T E=\int_{0}^{1} \operatorname{MTE}\left(u_{A}\right) \omega_{\operatorname{MPRTE}}\left(u_{A}\right) d u_{A}
$$

Where:

$$
\omega_{\text {MPRTE }}\left(u_{A}\right)=-\frac{\frac{\partial}{\partial \delta} F_{0}\left(u_{A}\right)}{\frac{\partial}{\partial \delta} E_{F_{0}}(A)}
$$

The definition of the weight depends on the type of policy change that is simulated. For instance, if a marginal increase in the probability of attending to a higher education institution is simulated, $p_{\delta}(t)=t+\delta$, then the relevant weight will be $\omega_{\operatorname{MPRTE}}(u)=f_{A}(u)$ while in the case that a proportional increase in the probability of attending to a higher education institution, $p_{\delta}(t)=(1+\delta) t$, the relevant weight will be $\omega_{\text {MPRTE}}(u)=u f_{A}(u) / E(A)$. It is also possible to simulate scenarios where marginal changes in an instrument are made, as a marginal increase in the average tuition costs, for example. Assuming that the instrument is the $j^{\text {th }}$ element in the $Z$ vector, a policy of the type $Z_{\delta}^{j}=Z^{j}+\delta$ will have a weight equal to $\omega_{\text {MPRTE }}(u)=f_{A}(u) f_{V}\left(F_{V}^{-1}(u)\right) / E\left(f_{V}(u)\right)$. All the relevant weights (including those of other treatment parameters, such as the Average Treatment Effect, ATE, and the Treatment on the Untreated, TUT) are presented in Tables 6 and $7 .{ }^{11}$

\footnotetext{
${ }^{11}$ Notice that the treatment parameters and even the instrumental variable estimations can be written as weighted average of the MTE. For more details see Heckman and Vytlacil (2005) and Heckman, Urzúa and Vytlacil (2006).
} 


\section{Data and Descriptive Statistics}

The data we use consider several sources. First, we use information from the administrative registry of the University Selection Test (PSU). This database contains information of individuals who took the test by late 2005, such as test scores and socioeconomic characteristics. Second, we use administrative information of enrollment in higher education institutions from 2007 to 2010. With this set of information we determined who took the PSU in 2005 and were enrolled in a higher education institution in those years. ${ }^{12}$

A third source of information is the administrative database of higher education graduates between 2007 and 2011. With this information we were able to determine which of the individuals that took the PSU 2005 graduated from a higher education institution in that time window. According to this rich and complete database, we determined our two groups of interest: (i) those who took the PSU in 2005 and never enrolled in a higher education institution (untreated group) and (ii) those who took the PSU in 2005, enrolled in a higher education institution and graduated from it (treated group). ${ }^{13}$

Finally, in order to obtain wages we merged our database with administrative data from the Chilean Unemployment Insurance system. This database contains information of dependent workers who have found a job or changed their jobs since october 2002, in addition to all workers who voluntarily affiliated to the system. ${ }^{14}$ With this database we were able to add the average wage between january and november 2012 for both groups. ${ }^{15}$ Our final sample has 36,376 observations of which 12,072 are treated individuals and 24,304 untreated.

Tables 8 and 9 present descriptive statistics of the variables used in the choice and in the wage equations. In the case of the choice equation we include PSU test scores (high school grades, math and language scores) as proxies of ability and their squares so we can capture any non-linear relations that may exist (Carneiro, Heckman and Vytlacil, 2011), a gender dummy (that is equal to 1 is the individual is male and 0 otherwise), age and geographical location dummies where living in the center of the country is the baseline. ${ }^{16}$ We also include in the choice equation dummies that account for type of school (where having studied in a public school is the base case), dummies of parents' education and of gross family income, which are divided into

\footnotetext{
${ }^{12}$ Since we do not have information for 2006 , we observe individuals who took the PSU in 2005, enrolled in a higher education in 2006 and did not dropout from it in that year. We are also able to observe those who took the PSU in 2005 and were not enrolled in 2007 in a higher education institution. It is important to note that this sample of students is quite stable in time.

${ }^{13}$ Other groups were not considered in the estimation.

${ }^{14}$ According to information of the Chilean Superintendence of Pensions, in 2012 nearly $94 \%$ of the dependent workers were affiliated to the Unemployment Insurance system.

${ }^{15}$ Given the high dispersion of wages we trimmed the highest and lowest $1 \%$ of wages in our sample.

${ }^{16}$ The information that we have regarding the regions of the country is before the new delimitation. In the old delimitation Chile is divided in 13 regions. We define north from the first to the fourth region, the center from the fifth to the seventh region plus the thirteenth region and the south from the eighth to the twelfth region.
} 
3 categories (from 0 to $\$ 278.000$ CLP, $\$ 278.000$ to $\$ 834.000$ CLP and more than $\$ 834.000$ CLP) and where the baseline is the lowest level of family income. ${ }^{17}$ We also include the size of the familiar group at the moment that the individual becomes a high school graduate and a dummy that indicates if the individual studied a non technical program in high school (the baseline is the case that the individual studied a technical program).

We consider different variables as instruments in the choice equation (and that are excluded from the wage equations, as suggested by Carneiro, Heckman and Vytlacil 2011). According to this article, to consider several instruments allows us to expand the range in which the MTE is identified. A first instrument is the average tuition cost of a higher education institution in the region that the individual lives in at the moment of taking the PSU. This variable affects the decision of attending or not to a higher education institution, as Cameron and Heckman (1998, 2001), Kane and Rouse (1995) and Kaufmann (2012) suggest. Additionally, we include the number of higher education institutions that existed in each region by 2005, year in which individuals were finishing their high school studies. This variable is related to the number of this type of institutions in the region and could affect the assessed decision. It is important to note that this variable is similar to the one considered in Card (1995) and Cameron and Taber (2004), which is the presence of a higher education institution near the students' household.

Another type of instruments that are considered in the literature are related to labor market variables. This is due to the fact that local economic conditions may affect the opportunity cost of those who are deciding to attend or not to higher education. Also, as noted in Carneiro, Heckman and Vytlacil (2011), labor market variables may affect the wages that the individual may perceive. Hence, we include in the wage equations the average log wage for each region in 2012. For the choice equation we include the average hourly wage for individuals aged between 19 and 24, for each region, which are constructed using the 2006 CASEN survey. Cameron and Heckman (1998) and Cameron and Taber (2004) consider similar variables to this one in their analyses. We include in the choice equation the average unemployment rate in 2005 for each region, following Cameron and Heckman (1998). Since it is likely that these instruments may be correlated with some socioeconomic variables (Carneiro, Heckman and Vytlacil, 2011), we include interactions of them with PSU test scores and their squares family income categories, parents' education and size of the familiar group.

In the case of the wage equations we include test scores and their squares, geographical location dummies, age, gender dummy, information related with the type of program that the individual followed in high school

\footnotetext{
${ }^{17}$ In 20061 US Dollar was equivalent to $\$ 530.2$ CLP.
} 
(i.e. technical or non technical), cumulative number of contributions to the Unemployment Insurance by 2011 (as a proxy of labor market experience) and, as mentioned previously, the average of the log wage in each region in 2012.

We see that the group that decided to attend a higher education institution obtains better test scores (in the PSU) and has a higher probability of living in the south of the country. We also see that this group come from wealthier households and that their parents are on average more educated than their peers that did not attend higher education. It is possible to observe that the untreated group is slightly older than the treated one and that the formers are on average more men relative to women. Finally, we see that those who decided to attend higher education come, with a higher likelihood, from private and private-voucher schools, and from smaller familiar groups than of those who did not attend higher education.

The untreated individuals have a higher probability of having studied a technical program at high school (in relation to the treated group) and more contributions to the Unemployment Insurance system. No important differences are acknowledged in relation to the average wage in 2012 in regions. We observe that who did not attend a higher education institution faced higher average tuition costs and lower unemployment rates in their regions. We see that those who attended to higher education faced lower average hourly wages in 2005 and that slightly lower number of higher education institutions were present in the regions they lived in 2005 .

\section{Results}

The estimation results of the choice equation are presented in Tables 10 and $11 .{ }^{18}$ We see that the test scores and their squares do not have a significant effect on the probability of attending to a higher education institution. The large number of interactions that we include capture these effects. We also see that individuals who live in the north and south of the country are more likely to attend higher education than their peers who live at the center of the country, and that the greater the family income, the greater the probability of being treated. We see that parents' schooling years does not have a statistically significant effect on the choice decision (again, caused by the large number of interactions that we include) while older and male individuals are less likely to study in higher education. It is possible to observe that attending to a public school and coming from a larger family reduces the probability of attending to a higher education

\footnotetext{
${ }^{18}$ Due to reasons of space, we omit the 60 coefficients of the interactions between instruments and socioeconomic variables. Results are available upon request.
} 
institution. Students who studied technical programs in high school have lower probabilities of studying in higher education.

Regarding the instruments, we see that higher tuition costs and higher unemployment rates reduce the probability of attending to a higher education institution. The latter may caused by economic problems in students' households and hence they are pushed to join the labor market. We see that higher hourly wages for individuals aged between 19 and 24 reduce the probability of attending to a higher education institution (higher opportunity cost), and that a larger number of higher education institutions in the region that the individuals resides increases the probability of attending to them. The propensity scores are presented in Figure 3. The common support of the propensity score is between 0.002 and 0.929 .

Table 12 presents the results of the estimation of the wage equations when a normal model is considered. We observe that the math test score is a strong predictor of wages, where higher test scores lead to higher wages, and that those who live at the north and south of the country obtain higher and lower wages than those of who live in the center, respectively. Older and male individuals earn higher wages. Having studied a non technical program in high school increases wages as well as having a larger number of cumulative contributions. We see that the log wages in 2012 en each region are strongly correlated with higher wages. Finally, we see that the coefficients that correspond to the propensity scores are positive and statistically significant.

The results of the semiparametric estimation of the wage equations are presented in Tables 13 and 14. It is important to note that in these results the function $K(p)$ is approximated by a degree 4 polynomial of the propensity score. We also present the results of the interactions of the propensity score and the mentioned regressions.

The estimated MTEs according to the wage equation parameters of each specification are presented in Figures 4 and 5 (both are conditioned in the mean of $X$ ). We observe that a negative slope exists in both cases, which suggests that individuals with higher levels of the unobservable $u_{A}$ (i.e. those with lower probabilities of attending to a higher education institution) obtain lower returns to higher education. Magnitudes of the MTEs differ significantly between specifications. We see that in the case of the semiparametric model there are individuals for whom is not possible to reject the hypothesis of null or even negative returns to higher education. ${ }^{19}$ This results goes in line with what other articles have found in the Chilean context,

\footnotetext{
${ }^{19}$ This does not occurs in the case of the normal model. These results show the importance of considering more flexible functional forms in the estimation.
} 
such as Reyes, Rodríguez and Urzúa (2013), in which negative returns for some individuals have also been documented.

With the purpose of analyzing with greater detail the estimations of the MTEs, we estimate local treatment parameters, different LATEs (Imbens and Angrist, 1994), in order to assess the economic returns to higher education as a function of diverse values of unobserved costs. For this, we consider the results obtained from the semiparametric specification, due to its greater flexibility. Table 15 presents the estimation results and the corresponding domain. We see that the returns to higher education decrease as greater values of $U_{A}$ are achieved. In some cases we can not reject the hypothesis of negative returns.

We test the hypothesis of selection in gains. In the case of the normal model we test the hypothesis $\rho_{1}=\rho_{0}$, which we reject (i.e. there is selection in gains). In the case of the semiparametric specification we test the joint hypothesis of equality of all LATEs. Table 16 presents the results of the joint test, in addition to equality tests of the adjacent LATEs. ${ }^{20}$ We can see that we reject the hypothesis that all LATEs are equal, a result that evidences the existence of selection in gains. Additionally we can observe that for the LATEs that correspond to lower levels of $U_{A}$, we can not reject the hypothesis of equality while the opposite occurs in the case of higher values of the unobservable, where the selection in gains happens to be strong among adjacent LATEs.

\subsection{Testing the Existence of Credit Constraints in Higher Education Access}

As introduced in previous sections, in order to analyze whether credit constraints in higher education access exist, it is necessary to compare the returns of those individuals who attended higher education with those who are at the margin of attending or not. The parameters of interest as the ATE, TT, TUT and different types of MPRTEs are presented in Table 17 (the estimated conditional probability density function, which is necessary for calculating the weights of the treatment paramaters, is presented in Figure 6) .We observe that under the normal model the returns to higher education of those who did not attend a higher education institution are quite large (81\%) and statistically significant, while the semiparametric specification yields substantially lower returns ( $10 \%$ for individuals who did not attend a higher education institution) that do not achieve statistical significance. A similar result can be seen in the case in which we consider the complete population, where important differences are acknowledged depending on the specification. These results evidence the convenience of using flexible functional forms.

Regarding the returns of those who are at the margin of attending higher education, measured by different

\footnotetext{
${ }^{20}$ We follow Carneiro, Heckman and Vytlacil (2011) for the estimation of the p-values of these tests.
} 
policy changes, results show that the returns are quite high and heterogenous, and slightly lower when the semiparametric model is taken into account.

Although the heterogeneity present in the MPRTEs, we see that they are never greater than the TT. A formal test is presented in Table 18. In it, we test the null hypothesis of $T T=M P R T E$. The results reject all of these hypotheses.

\subsubsection{Credit Constraints and Household Income}

Household income is an important determinant at the moment of deciding to attend or not higher education. Households with lower income levels will face more difficulties at the moment this decision is taken. In this section, we test the existence of credit constraints in higher education access for two groups of individuals: (1) those who belong to households with an income between $\$ 0$ and $\$ 278,000$ CLP (category 1 of income level) and those with an income between $\$ 278,000$ and $\$ 834,000$ CLP (category 2 of income level) and (2) those who belong to households with an income of at least $\$ 834,000$ CLP (category 3 income level). These income categories are measured at the moment individuals face the decision of attending or not a higher education institution.

We repeat the same exercise that was performed in the previous section. We estimate conditional probability density functions for both groups, in order to calculate the weights of the treatment parameters. Figures 7 and 8 present the density estimations. On the other hand, Figures 9 and 10 show the estimated MTEs according to the normal model, for both groups. Figures 11 and 12 present the equivalent in the case of the semiparametric specification. We see important differences in relation to returns to higher education, where individuals from higher income households obtain higher returns, no matter the specification that is considered.

The treatment parameters according to different specifications and household income categories are presented in Tables 19 and 20. We observe that the treatment parameters differ significantly in terms of magnitude and statistical significance. In this sense the semiparametric model yields more credible results.

Finally, Tables 21 and 22 show the results of the hypothesis test $T T=M P R T E$ for each group. In Table 21 we see that in the case of the normal model all of the hypotheses are rejected, for those who belong to the first group. However, when considering the semiparametric specification we see that although

all of the hypotheses are rejected with a $93 \%$ of confidence, these rejections are not as evident as in the normal specification. Table 22 presents the results for the second group. Similar results are obtained when 
considering the normal specification. However, when the semiparametric model is taken into account we see that we can not reject the null hypothesis in one case, p-value equal to 0.207 , and a p-value about 0.06 is obtained in the other case.

These results show that the presence of credit constraints in higher education access is not evident for individuals from the first, low income, group. This is not the case for the higher income group for which some evidence of credit constraints is observed. This latter result may indicate that the increase of grants and loans of 2006 was necessary, although the impact of the magnitude spent is not clear. Future research should assess the effects of the large increase of grants and loans between 2006 and 2012 on credit constraints. In the case that no credit constraints were found, a feasible hypothesis, from an economic point of view, would be that a further increase in grants and loans would not be required (ceteris paribus).

\section{Concluding Remarks}

The recent expansion of financial aids for higher education, which has turned out to be an international phenomenon, calls to take this cautiously, especially in a context of limited fiscal resources. This is due to the fact that the fiscal burden may heavily increase and that public resources may have been delivered to individuals who may have privately obtained them. Thus, a reasonable objective is expanding these aids to individuals who are credit constrained.

The difficulty for identifying credit constrained individuals has lead to the development of different approaches in order to do so. Articles such as Kane (1996, 2007), Cameron and Heckman (2001), and Rau, Rojas and Urzúa (2013) are focused on assessing the effects that the access to financial aids has on the probability of enrolling in higher education. Others like Carneiro and Heckman (2002), Cameron and Taber (2004) and Kaufmann (2012), consider the analysis of higher education returns in order to assess the existence of credit constraints.

Unlike previous works, this article tests the existence of credit constraints in higher education access by considering actual marginal returns to education, in a context of unobserved heterogeneity. This is an important contribution to a literature in which no concluding results exist. In order to test the existence of credit constraints we compare the returns to higher education of those who attended it with those of who are at the margin of attending it. Our argument follows the intuition of Carneiro and Heckman (2002): if individuals that are at the margin of attending to a higher education institution had larger returns than 
those that are actually attending to it, then the formers would have faced unobservable barriers in the access to higher education, that may be interpreted as credit constraints.

In our empirical strategy we simulate diverse marginal policy changes in order to identify individuals who are at the margin of attending (or not) higher education. Thus, by considering the Marginal Treatment Effect (MTE) presented in Heckman and Vytlacil (1999, 2005) and Heckman, Urzúa and Vytlacil (2006), we estimate the economic returns to higher education of this group and then compare them with those of who decided to attend a higher education institution. We consider a complete administrative database that includes information from national standardized test scores (the University Selection Test) in 2005, higher education enrollment and graduate registries and wages that individuals earned between 2007 and 2012 , from the Chilean Unemployment Insurance system.

Our results suggest the existence of selection in gains. That is, individuals with lower unobservable costs of attending a higher education institution experiment larger economic returns. Additionally, conditional on the existing situation in Chile in 2006 and before the large expansion in grants and loans that occurred between 2006 and 2012, the returns of those who are at the margin are lower than those of who decided to attend higher education. This result is robust to different simulations of policy changes and to different functional forms. Hence, no evidence of credit constraints in higher education can be acknowledged However, when conditioning on household income levels, we find that for higher income households some evidence of credit constraints is found, although it is not categorical. These results would seem to support the large expansion of financial aids that occurred between 2006 and 2012 in Chile. Future research should assess if credit constraints are still present, given the actual context of grants and loans, and hence provide empirical evidence that supports or oppose a new expansion of financial aids. 


\section{References}

Becker, G.S. (1967). "Human Capital: A Theoretical and Empirical Analysis, with Special Reference to Education", University of Chicago Press.

Cameron, S.V. and J.J. Heckman (1998). "Life Cycle Schooling and Dynamic Selection Bias: Models and Evidence for Five Cohorts of American Males", Journal of Political Economy, 106(2): 262-333.

Cameron, S.V. and J.J. Heckman (2001). "The Dynamics of Educational Attainment for Black, Hispanic and White Males", Journal of Political Economy, 109(3): 455-499.

Cameron, S.V. and C. Taber (2004). "Estimation of Educational Borrowing Constraints Using Returns to Schoolings", Journal of Political Economy, 112(1): 132-182.

Card, D. (1994). "Earnings, Schooling, and Ability Revisited", National Bureau of Economic Research Working Paper Series, No. 4832.

Card, D. (1995). "Using Geographic Variation in College Proximity to Estimate the Return to Schooling", Aspects of Labour Market Behaviour: Essays in Honor of John Vanderkamp, ed. Louis Christofides, E. Kenneth Grant and Robert Swidinsky, 201-222. University of Toronto Press.

Card, D. (2001). "Estimating the Return to Schooling: Progress on Some Persistent Econometric Problems", Econometrica, 69(5): 1127-1160.

Carneiro, P. and J.J. Heckman (2002). "The Evidence on Credit Constraints in Post-Secondary Schooling", Economic Journal, 112(482): 705-734.

Carneiro, P., J. J. Heckman, and E. Vytlacil (2010). "Evaluating Marginal Policy Changes and the Average Effect of Treatment for Individuals at the Margin", Econometrica, 78(1): 377-394.

Carneiro, P., J. J. Heckman, and E. Vytlacil (2011). "Estimating Marginal Returns to Education", American Economic Review, 101(6): 2754-2781.

Espinoza, O., E. Fecci, L. E. Gonzalez, V. Kluge, A. Mora, O. Ocaranza, J. P. Prieto, and E. Rodriguez (2006). "Informe: Educación Superior en Iberoamérica El Caso de Chile," Centro Interuniversitario de Desarrollo CINDA.

Fan, J. and I. Gijbels (1996). "Local Polynomial Modelling and its Applications", New York: Chapman Hall. Heckman, J.J., H. Ichimura, J. Smith and P.E. Todd (1998). "Characterizing Selection Bias Using Experimental Data", Econometrica, 66(5): 1017-1098. 
Heckman, J.J. and R. Robb (1985). "Alternative Methods for Evaluating the Impact of Interventions", Longitudinal Analysis of Labor Market Data, Vol. 10, Cambridge University Press, New York.

Heckman, J.J. and E. Vytlacil (1999). "Local Instrumental Variables and Latent Variable Models for Identifying and Bounding Treatment Effects", Proceedings of the National Academy of Sciences, 96(8): 4730-4734.

Heckman, J.J. and E. Vytlacil (2001). "Policy-Relevant Treatment Effects", American Economic Review, 91(2): 107-111.

Heckman, J.J. and E. Vytlacil (2005). "Structural Equations, Treatment Effects and Econometric Policy Evaluation", Econometrica, 73(3): 669-738.

Heckman, J.J., S. Urzúa and E. Vytlacil (2006). "Understanding Instrumental Variables in Models with Essential Heterogeneity", The Review of Economics and Statistics, 88(3): 389-432.

Imbens, G. and J. Angrist (1994). "Identification and Estimation of Local Average Treatment Effects", Econometrica, 62(2): 467-475.

Kane, T. J. (1996). "College Cost, Borrowing Constraints and the Timing of College Entry", Eastern Economic Journal, 22(2): 181-194.

Kane, T. J. (2007). "Evaluating the Impact of the D.C. Tuition Assistance Grant Program", Journal of Human Resources, 42(3): 555-582.

Kane, T.J. and C.E. Rouse (1995). "Labor-Market Returns to Two- and Four-Year College", American Economic Review, 85(3): 600-614.

Kaufmann, K.M. (2012). "Understanding the Income Gradient in College Attendance in Mexico: The Role of Heterogeneity in Expected Returns", Working Paper.

Keane, M., and K. Wolpin (2001). "The Effect of Parental Transfers and Borrowing Constraints on Educational Attainment", International Economic Review, 42(4): 1051-1103.

Lochner, L., and A. Monge-Naranjo (2011). "The Nature of Credit Constraints and Human Capital," American Economic Review, 101(6): 2487-2529.

Rau, T., E. Rojas and S. Urzúa (2013). "Loans for Higher Education: Does the Dream Come True?", National Bureau of Economic Research Working Paper Series, No. 19138.

Reyes, L., J. Rodríguez and S. Urzúa (2013). "Heterogenous Economic Returns to Postsecondary Degrees: Evidence from Chile", National Bureau of Economic Research Working Paper Series, No. 18817. 
Robinson, P.M. (1988). "Root-N-Consistent Semiparametric Regression", Econometrica, 56(4): 931-954.

Roy, A.D. (1951). "Some Thoughts on the Distribution of Earnings", Oxford Economic Papers, 39(2): 135146.

Taber, C. (2001). "The Rising College Premium in the Eighties: Return to College or Return to Unobserved Ability?", Review of Economic Studies, 68(3): 665-691.

Willis, R.J. and S. Rosen (1979). "Education and Self-Selection", Journal of Political Economy, 87(5): S7S36. 


\section{Tables}

Table 1: Higher Education Enrollment According to Type of Institution (2011)

\begin{tabular}{rrr}
\hline \hline Type of Institution & Number of Students & $\%$ \\
\hline Technical Institue & 138,635 & $13.0 \%$ \\
Professional Institue & 267,766 & $25.1 \%$ \\
University & 661,862 & $62.0 \%$ \\
\hline Total & $1,068,263$ & $100 \%$ \\
\hline
\end{tabular}

Source: Chilean Ministry of Education. 
Table 2: Main Benefits available in 2006 (Credits and Scholarships)

\begin{tabular}{|c|c|c|}
\hline Benefits & Description & Requirements \\
\hline Fondo Solidario de Crédito & This credit covers the total amount of the reference tuition & (i) Being enrrolled in an institution that belongs to the Consejo de \\
\hline Universitario (FSCU) & $\begin{array}{l}\text { fee and considers an annual real interest rate of } 2 \% \text {, } \\
\text { which starts being paid } 2 \text { years after graduation }(15 \text { years } \\
\text { is the maximum time limit) and it is income contingent }(5 \%) \text {. }\end{array}$ & $\begin{array}{l}\text { Rectores de Universidades Chilenas }(\mathrm{CRUCH}) \text {, (ii) being Chilean, (iii) obtain at least } \\
475 \text { points on average in the PSU test of language and mathematics and } \\
\text { (iv) belong to the poorest } 80 \% \text { of the population. }\end{array}$ \\
\hline $\begin{array}{l}\text { Crédito con Aval del Estado } \\
\text { (CAE) }\end{array}$ & $\begin{array}{l}\text { This credit covers up to the total amount of the reference tuition } \\
\text { fee and considers an annual real interest rate that depends } \\
\text { on the licitation between the State and private banks } \\
\text { (up to } 2011 \text { the rate was around } 5.6 \% \text { ). The CAE } \\
\text { must start to be paid } 18 \text { months after graduation (the maximum } \\
\text { time period to pay is } 20 \text { years) and considers a fixed monthly fee. }\end{array}$ & $\begin{array}{l}\text { (i) Being enrolled in an autonomous and certified higher education institution, } \\
\text { (ii) being chilean, (iii) obtain at least } 475 \text { points on average in the } \\
\text { language and mathematics tests of the PSU an average GPA of at least } 5.3 \\
\text { and (iv) being socially needed as requested by the rules of the CAE. }\end{array}$ \\
\hline Beca Bicentenario & Scholarship which covers the full reference tuition fee. & $\begin{array}{l}\text { (i) Being enrolled in an institution that is member of the Consejo de } \\
\text { Rectores de Universidades Chilenas (CRUCH), (ii) being chilean, } \\
\text { (iii) obtain at least } 550 \text { points on average in the language and mathematics tests } \\
\text { of the PSU and (iv) belong to the poorest } 40 \% \text { of the population. }\end{array}$ \\
\hline Beca Juan Gómez Millas & $\begin{array}{l}\text { Scholarship which covers the full reference tuition fee } \\
\text { up to } \$ 1,150,000 \text { CLP. }\end{array}$ & $\begin{array}{l}\text { (i) Being enrolled in a certified institution, (ii) being chilean, (iii) } \\
\text { having graduated from a public or private-voucher school, (iv) obtain at } \\
\text { least } 640 \text { points on average in the language and mathematics tests of the PSU and } \\
\text { (v) belong to the poorest } 40 \% \text { of the population. }\end{array}$ \\
\hline Beca de Pedagogía & $\begin{array}{l}\text { This scholarship covers the full reference tuition fee } \\
\text { up to } \$ 1,150,000 \text { CLP. }\end{array}$ & $\begin{array}{l}\text { (i) Being enrolled in Pedagogy in any certified higher education } \\
\text { institution, (ii) having applied to pedagogy as a first option, (iii) being chilean, } \\
\text { (iv) obtain at least an average GPA of } 6.0 \text { and (v) obtain at least } \\
600 \text { points on average between the language and mathematics tests of the PSU. }\end{array}$ \\
\hline $\begin{array}{l}\text { Beca para Hijos Profesionales } \\
\text { de la Educación }\end{array}$ & $\begin{array}{l}\text { This scholarship covers the full reference tuition fee } \\
\text { up to } \$ 1,150,000 \text { CLP. }\end{array}$ & $\begin{array}{l}\text { (i) Being enrolled in any autonomous higher education institution, } \\
\text { (ii) being chilean, (iii) being son/daughter of an educational system worker } \\
\text { with a contract in the public or private-voucher sector, (iv) obtain at } \\
\text { least a GPA of } 5.5 \text {, (v) obtain at least } 500 \text { points on average between the } \\
\text { language and mathemathics tests of the PSU and (vi) belong to the poorest } 80 \% \\
\text { of the population. }\end{array}$ \\
\hline Beca Nuevo Milenio & $\begin{array}{l}\text { This scholarship covers the full tuition fee } \\
\text { up to } \$ 500,000 \text { CLP. }\end{array}$ & $\begin{array}{l}\text { (i) Being enrolled in a technical degree programr eligible by the Ministry of } \\
\text { Education or being enrolled in a technical degree program in a certified Professional } \\
\text { Institute, (ii) being chilean, (iii) obtain an average GPA of at least a } 5.0 \text { for technical } \\
\text { degrees and } 5.5 \text { for professional degrees and (iv) belong to the poorest } \\
40 \% \text { of the population. }\end{array}$ \\
\hline Beca Indígena & $\begin{array}{l}\text { Subsidy paid in } 10 \text { monthly payments }(\$ 607,000 \text { CLP } \\
\text { in total in } 2013)\end{array}$ & $\begin{array}{l}\text { (i) Have a certified indigenous background, (ii) certify vulnerability conditions through } \\
\text { social information provided by the municipality and (iii) obtain an average GPA of } \\
\text { at least } 4.5 \text { in higher education. }\end{array}$ \\
\hline Beca Presidente de la República & $\begin{array}{l}\text { Monthly Subsidy equivalent to } 1.24 \text { UTM } \\
\text { (1 UTM corresponds to } \$ 42,178 \text { CLP as of July } 2014)\end{array}$ & $\begin{array}{l}\text { (i) Certifyt to be a regular student in a higher education institution, (ii) obtain } \\
\text { an average GPA of } 6.0 \text { and (iii) certify vulnerability conditions. }\end{array}$ \\
\hline
\end{tabular}


Table 3: Coverage of Higher Education Grants by Quintiles of Income

\begin{tabular}{rrrrrr}
\hline \hline Quintile & \multicolumn{5}{c}{ Year } \\
& 2000 & 2003 & 2006 & 2009 & 2011 \\
\hline \hline I & $20.2 \%$ & $14.9 \%$ & $21.1 \%$ & $23.3 \%$ & $37.1 \%$ \\
II & $9.5 \%$ & $13.0 \%$ & $17.8 \%$ & $23.8 \%$ & $26.2 \%$ \\
III & $9.5 \%$ & $13.2 \%$ & $13.0 \%$ & $18.6 \%$ & $25.3 \%$ \\
IV & $5.7 \%$ & $10.8 \%$ & $11.8 \%$ & $13.3 \%$ & $18.9 \%$ \\
V & $1.8 \%$ & $7.0 \%$ & $8.5 \%$ & $8.4 \%$ & $11.1 \%$ \\
\hline Total & $6.3 \%$ & $10.4 \%$ & $12.5 \%$ & $15.3 \%$ & $21.4 \%$ \\
\hline \hline
\end{tabular}

Source: Authors' elaboration based on CASEN 2000, 2003, 2006, 2009 and 2011 surveys.

Table 4: Coverage of Higher Education Loans by Quintiles of Income

\begin{tabular}{rrrrrr}
\hline Quintile & \multicolumn{5}{c}{ Year } \\
& 2000 & 2003 & 2006 & 2009 & 2011 \\
\hline \hline I & $37.5 \%$ & $40.2 \%$ & $45.2 \%$ & $46.3 \%$ & $56.5 \%$ \\
II & $39.3 \%$ & $44.0 \%$ & $42.8 \%$ & $45.9 \%$ & $52.4 \%$ \\
III & $35.7 \%$ & $34.8 \%$ & $35.4 \%$ & $44.7 \%$ & $46.7 \%$ \\
IV & $27.0 \%$ & $28.7 \%$ & $36.3 \%$ & $38.1 \%$ & $39.8 \%$ \\
V & $13.1 \%$ & $16.4 \%$ & $21.0 \%$ & $18.2 \%$ & $27.0 \%$ \\
\hline Total & $25.7 \%$ & $27.9 \%$ & $33.0 \%$ & $34.9 \%$ & $41.7 \%$ \\
\hline \hline
\end{tabular}

Source: Authors' elaboration based on CASEN 2000, 2003, 2006, 2009 and 2011 surveys.

Table 5: Coverage of Higher Education Grants or Loans by Quintiles of Income

\begin{tabular}{rrrrrr}
\hline \hline Quintile & \multicolumn{5}{c}{ Year } \\
& 2000 & 2003 & 2006 & 2009 & 2011 \\
\hline \hline I & $50.5 \%$ & $48.5 \%$ & $56.2 \%$ & $57.4 \%$ & $71.6 \%$ \\
II & $44.1 \%$ & $51.1 \%$ & $52.1 \%$ & $57.3 \%$ & $63.0 \%$ \\
III & $39.0 \%$ & $42.7 \%$ & $42.3 \%$ & $53.4 \%$ & $56.3 \%$ \\
IV & $30.1 \%$ & $34.6 \%$ & $41.8 \%$ & $44.3 \%$ & $49.5 \%$ \\
V & $14.2 \%$ & $22.7 \%$ & $27.7 \%$ & $24.4 \%$ & $33.7 \%$ \\
\hline Total & $28.8 \%$ & $34.7 \%$ & $40.0 \%$ & $42.8 \%$ & $51.3 \%$ \\
\hline \hline
\end{tabular}

Source: Authors' elaboration based on CASEN 2000, 2003, 2006, 2009 and 2011 surveys. 
Table 6: Weights for Treatment Parameters

\begin{tabular}{rr}
\hline \hline Parameter & Weight \\
\hline Average Treatment Effect (ATE) & $\omega_{A T E}(x, u)=1$ \\
Treatment on the Treated (TT) & $\omega_{T T}(x, u)=\left[\int_{u}^{1} f(a \mid X=x) d a\right] \frac{1}{E(P \mid X=x)}$ \\
Treatment on the Untreated (TUT) & $\omega_{T U T}(x, u)=\left[\int_{0}^{u} f(a \mid X=x) d a\right] \frac{1}{E(1-P \mid X=x)}$ \\
Marginal Policy Relevant Treatment Effect (MPRTE) & $\omega_{M P R T E}(x, u)=-\frac{\frac{\partial}{\partial \delta} F_{0}(u \mid X=x)}{\frac{\partial}{\partial \delta} E_{F_{0}}(A \mid X=x)}$ \\
\hline \hline
\end{tabular}

Source: Heckman and Vytlacil (2005) and Carneiro, Heckman and Vytlacil (2010).

Table 7: Weights for Different MPRTEs

\begin{tabular}{rr}
\hline \hline Type of Policy & Weight \\
\hline$P_{\delta}=P+\delta$ & $\omega_{M P R T E}(x, u)=f_{P \mid X}(u)$ \\
$P_{\delta}=P(1+\delta)$ & $\omega_{M P R T E}(x, u)=\frac{u f_{P \mid X}(u)}{E(P \mid X)}$ \\
$Z_{\delta}^{j}=Z^{j}+\delta$ & $\omega_{M P R T E}(x, u)=\frac{f_{P \mid X}(u) f_{V \mid X}\left(F_{V \mid X}^{-1}(u)\right)}{E\left(f_{V \mid X}\left(\mu_{A}(Z) \mid X\right)\right)}$ \\
\hline \hline
\end{tabular}

Source: Carneiro, Heckman and Vytlacil (2010). 
Table 8: Descriptive Statistics

\begin{tabular}{|c|c|c|}
\hline Variable & Attend & Do not Attend \\
\hline \multirow[t]{2}{*}{ High School GPA } & 0.391 & -0.194 \\
\hline & $(0.974)$ & $(0.951)$ \\
\hline \multirow[t]{2}{*}{ Language } & 0.455 & -0.229 \\
\hline & $(0.939)$ & $(0.924)$ \\
\hline \multirow[t]{2}{*}{ Mathematics } & 0.449 & -0.23 \\
\hline & $(0.971)$ & $(0.945)$ \\
\hline \multirow[t]{2}{*}{ North } & 0.104 & 0.127 \\
\hline & $(0.306)$ & $(0.333)$ \\
\hline \multirow[t]{2}{*}{ South } & 0.253 & 0.203 \\
\hline & $(0.435)$ & $(0.402)$ \\
\hline \multirow[t]{2}{*}{ Household Income $(\$ 278.000-\$ 834.000)$} & 0.334 & 0.253 \\
\hline & $(0.472)$ & $(0.435)$ \\
\hline \multirow[t]{2}{*}{ Household Income ( $\$ 834.000$ and more) } & 0.14 & 0.055 \\
\hline & $(0.347)$ & $(0.228)$ \\
\hline \multirow[t]{2}{*}{ Father's Education: Between 8 and 12 years } & 0.216 & 0.282 \\
\hline & $(0.411)$ & $(0.45)$ \\
\hline \multirow[t]{2}{*}{ Father's Education: 12 years } & 0.349 & 0.353 \\
\hline & $(0.477)$ & $(0.478)$ \\
\hline \multirow[t]{2}{*}{ Father's Education: More than 12 years } & 0.345 & 0.208 \\
\hline & $(0.475)$ & $(0.406)$ \\
\hline \multirow[t]{2}{*}{ Mother's Education: Between 8 and 12 years } & 0.235 & 0.322 \\
\hline & $(0.424)$ & $(0.467)$ \\
\hline \multirow[t]{2}{*}{ Mother's Education: 12 years } & 0.374 & 0.364 \\
\hline & $(0.484)$ & $(0.481)$ \\
\hline \multirow[t]{2}{*}{ Mother's Education: More than 12 years } & 0.303 & 0.163 \\
\hline & $(0.46)$ & $(0.37)$ \\
\hline
\end{tabular}

Note: Standard deviations in parenthesis. 
Table 9: Descriptive Statistics (Continuation)

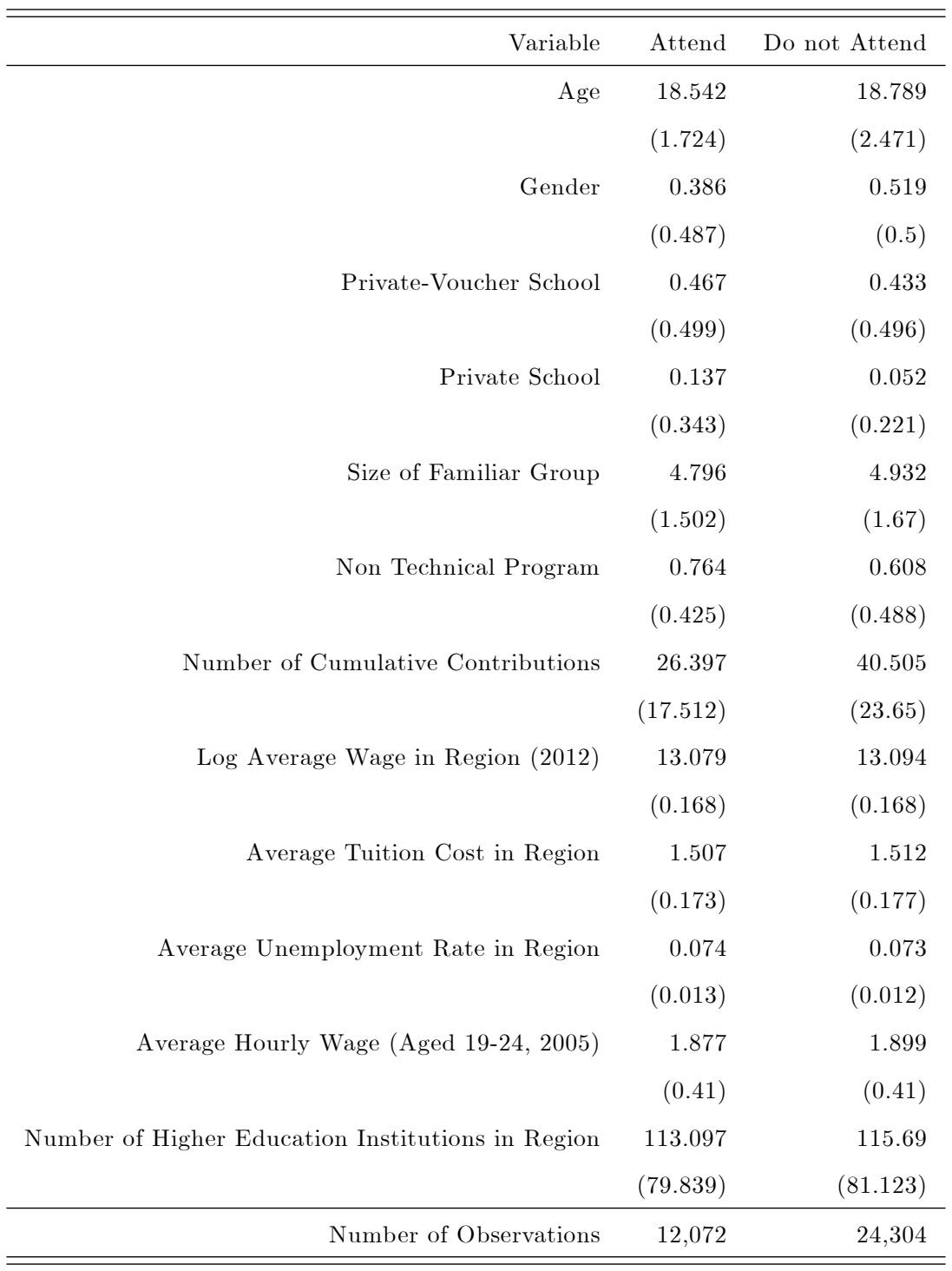

Notes: Standard deviations in parethnesis. The average tuition cost in the region is expressed in millions of Chilean pesos while the average hourly wage for individuals aged between 19 and 24 years is expressed in thousands of Chilean pesos. 
Table 10: Choice Equation Estimation Results

\begin{tabular}{|c|c|}
\hline Variable & Coefficient \\
\hline \multirow[t]{2}{*}{ High School GPA } & 0.361 \\
\hline & $(0.241)$ \\
\hline \multirow[t]{2}{*}{ Language } & -0.052 \\
\hline & $(0.292)$ \\
\hline \multirow[t]{2}{*}{ Mathematics } & -0.023 \\
\hline & $(0.297)$ \\
\hline \multirow[t]{2}{*}{ High School GPA (Squared) } & -0.153 \\
\hline & $(0.186)$ \\
\hline \multirow[t]{2}{*}{ Language (Squared) } & -0.239 \\
\hline & $(0.184)$ \\
\hline \multirow[t]{2}{*}{ Mathematics (Squared) } & -0.092 \\
\hline & $(0.188)$ \\
\hline \multirow[t]{2}{*}{ North } & 0.116 \\
\hline & $(0.04)$ \\
\hline \multirow[t]{2}{*}{ South } & 0.243 \\
\hline & $(0.029)$ \\
\hline \multirow[t]{2}{*}{ Household Income $(\$ 278.000$ - $\$ 834.000)$} & 0.682 \\
\hline & $(0.497)$ \\
\hline \multirow[t]{2}{*}{ Household Income (\$834.000 and more) } & 2.611 \\
\hline & $(0.914)$ \\
\hline \multirow[t]{2}{*}{ Father's Education: Between 8 and 12 years } & -0.482 \\
\hline & $(0.678)$ \\
\hline \multirow[t]{2}{*}{ Father's Education: 12 years } & -0.822 \\
\hline & $(0.698)$ \\
\hline \multirow[t]{2}{*}{ Father's Education: More than 12 years } & -1.058 \\
\hline & $(0.816)$ \\
\hline
\end{tabular}

Notes: Standard errors in parenthesis. Following Carneiro, Heckman and Vytlacil (2011), we include in the regression interactions of the test scores (and their squares), household income categories, parents' education and size of the familiar group with the 4 considered instruments. 
Table 11: Choice Equation Estimation Results (Continuation)

\begin{tabular}{|c|c|}
\hline Variable & Coefficient \\
\hline \multirow[t]{2}{*}{ Mother's Education: Between 8 and 12 years } & -0.542 \\
\hline & $(0.68)$ \\
\hline \multirow[t]{2}{*}{ Mother's Education: 12 years } & -0.955 \\
\hline & $(0.707)$ \\
\hline \multirow[t]{2}{*}{ Mother's Education: More than 12 years } & -0.878 \\
\hline & $(0.854)$ \\
\hline \multirow[t]{2}{*}{ Age } & -0.021 \\
\hline & $(0.004)$ \\
\hline \multirow[t]{2}{*}{ Gender } & -0.289 \\
\hline & $(0.016)$ \\
\hline \multirow[t]{2}{*}{ Private-Voucher School } & 0.101 \\
\hline & $(0.016)$ \\
\hline \multirow[t]{2}{*}{ Private School } & 0.126 \\
\hline & $(0.034)$ \\
\hline \multirow[t]{2}{*}{ Size of Familiar Group } & -0.37 \\
\hline & $(0.128)$ \\
\hline \multirow[t]{2}{*}{ Non Technical Program } & 0.157 \\
\hline & $(0.017)$ \\
\hline \multirow[t]{2}{*}{ Average Tuition Cost in Region } & -1.696 \\
\hline & $(0.515)$ \\
\hline \multirow[t]{2}{*}{ Average Unemployment Rate in Region } & -8.238 \\
\hline & $(3.51)$ \\
\hline \multirow[t]{2}{*}{ Average Hourly Wage (Aged 19-24, 2005) } & -0.986 \\
\hline & $(0.338)$ \\
\hline \multirow[t]{2}{*}{ Number of Higher Education Institutions in Region } & 0.008 \\
\hline & $(0.002)$ \\
\hline \multirow[t]{2}{*}{ Constant } & 3.909 \\
\hline & $(0.933)$ \\
\hline
\end{tabular}

Notes: Standard errors in parenthesis. Following Carneiro, Heckman and Vytlacil (2011), we include in the regression interactions of the test scores (and their squares), household income categories, parents' education and size of the familiar group with the 4 considered instruments. 
Table 12: Wage Equations Estimation Results (Normal Model)

\begin{tabular}{|c|c|c|}
\hline \multirow[t]{2}{*}{ Variable } & \multicolumn{2}{|c|}{ Coefficient } \\
\hline & Treated & Untreated \\
\hline \multirow[t]{2}{*}{ High School GPA } & 0.006 & -0.007 \\
\hline & $(0.009)$ & $(0.005)$ \\
\hline \multirow[t]{2}{*}{ Language } & 0.009 & -0.043 \\
\hline & $(0.011)$ & $(0.007)$ \\
\hline \multirow[t]{2}{*}{ Mathematics } & 0.123 & 0.043 \\
\hline & $(0.011)$ & $(0.008)$ \\
\hline \multirow[t]{2}{*}{ High School GPA (Squared) } & 0.007 & 0.001 \\
\hline & $(0.005)$ & $(0.003)$ \\
\hline \multirow[t]{2}{*}{ Language (Squared) } & -0.008 & -0.009 \\
\hline & $(0.005)$ & $(0.003)$ \\
\hline \multirow[t]{2}{*}{ Mathematics (Squared) } & 0.034 & 0.017 \\
\hline & $(0.004)$ & $(0.004)$ \\
\hline \multirow[t]{2}{*}{ North } & 0.075 & 0.072 \\
\hline & $(0.019)$ & $(0.012)$ \\
\hline \multirow[t]{2}{*}{ South } & -0.03 & -0.055 \\
\hline & $(0.015)$ & $(0.011)$ \\
\hline \multirow[t]{2}{*}{ Age } & 0.007 & 0.008 \\
\hline & $(0.003)$ & $(0.002)$ \\
\hline \multirow[t]{2}{*}{ Gender } & 0.078 & 0.173 \\
\hline & $(0.014)$ & $(0.01)$ \\
\hline \multirow[t]{2}{*}{ Non Technical Program } & -0.069 & -0.066 \\
\hline & $(0.015)$ & $(0.009)$ \\
\hline \multirow[t]{2}{*}{ Cumulative Number of Contributions } & 0.006 & 0.009 \\
\hline & $(0.000)$ & $(0.000)$ \\
\hline \multirow[t]{2}{*}{ Log Average Wage in Region (2012) } & 0.358 & 0.390 \\
\hline & $(0.035)$ & $(0.025)$ \\
\hline \multirow[t]{2}{*}{$\rho$} & 0.165 & 0.334 \\
\hline & $(0.045)$ & $(0.039)$ \\
\hline \multirow[t]{2}{*}{ Constant } & 8.209 & 6.767 \\
\hline & $(0.462)$ & $(0.338)$ \\
\hline
\end{tabular}

Note: Standard errors in parenthesis. 
Table 13: Wage Equations Estimation Results (Semiparametric Model)

\begin{tabular}{|c|c|}
\hline Variable & Coefficient \\
\hline High School GPA & 0.006 \\
\hline & $(0.012)$ \\
\hline Language & -0.067 \\
\hline & $(0.019)$ \\
\hline Mathematics & 0.031 \\
\hline & $(0.02)$ \\
\hline \multirow[t]{2}{*}{ High School GPA (Squared) } & -0.001 \\
\hline & $(0.006)$ \\
\hline \multirow[t]{2}{*}{ Language (Squared) } & -0.021 \\
\hline & $(0.007)$ \\
\hline \multirow[t]{2}{*}{ Mathematics (Squared) } & 0.011 \\
\hline & $(0.007)$ \\
\hline \multirow[t]{2}{*}{ North } & 0.192 \\
\hline & $(0.02)$ \\
\hline \multirow[t]{2}{*}{ South } & -0.004 \\
\hline & $(0.019)$ \\
\hline \multirow[t]{2}{*}{ Age } & 0.002 \\
\hline & $(0.003)$ \\
\hline \multirow[t]{2}{*}{ Gender } & 0.28 \\
\hline & $(0.017)$ \\
\hline \multirow[t]{2}{*}{ Non Technical Program } & -0.060 \\
\hline & $(0.017)$ \\
\hline \multirow[t]{2}{*}{ Log Average Wage in Region (2012) } & 0.391 \\
\hline & $(0.043)$ \\
\hline \multirow[t]{2}{*}{ Cumulative Number of Contributions } & 0.010 \\
\hline & $(0.000)$ \\
\hline
\end{tabular}

Note: Standard errors in parenthesis. 
Table 14: Wage Equations Estimation Results (Semiparametric Model), Continuation

\begin{tabular}{|c|c|}
\hline Variable & Coeficiente \\
\hline \multirow[t]{2}{*}{$\hat{P}(Z) \times$ High School GPA } & -0.017 \\
\hline & $(0.040)$ \\
\hline \multirow[t]{2}{*}{$\hat{P}(Z) \times$ Language } & 0.106 \\
\hline & $(0.058)$ \\
\hline \multirow[t]{2}{*}{$\hat{P}(Z) \times$ Mathematics } & 0.101 \\
\hline & $(0.058)$ \\
\hline \multirow[t]{2}{*}{$\hat{P}(Z) \times$ High School GPA (Squared) } & 0.02 \\
\hline & $(0.016)$ \\
\hline \multirow[t]{2}{*}{$\hat{P}(Z) \times$ Language $($ Squared $)$} & 0.015 \\
\hline & $(0.015)$ \\
\hline \multirow{4}{*}{$\hat{P}(Z) \times$ Mathematics $($ Squared $)$} & 0.036 \\
\hline & $(0.013)$ \\
\hline & -0.400 \\
\hline & $(0.058)$ \\
\hline \multirow[t]{2}{*}{$\hat{P}(Z) \times$ South } & -0.110 \\
\hline & $(0.046)$ \\
\hline \multirow[t]{2}{*}{$\hat{P}(Z) \times$ Age } & 0.035 \\
\hline & $(0.009)$ \\
\hline \multirow{2}{*}{$\hat{P}(Z) \times$ Gender } & -0.437 \\
\hline & $(0.046)$ \\
\hline \multirow[t]{2}{*}{$\hat{P}(Z) \times$ Non Technical Program } & -0.078 \\
\hline & $(0.055)$ \\
\hline \multirow[t]{2}{*}{$\hat{P}(Z) \times \log$ Average Wage in Region (2012) } & -0.06 \\
\hline & $(0.109)$ \\
\hline \multirow[t]{2}{*}{$\hat{P}(Z) \times$ Number of Contributions } & -0.012 \\
\hline & $(0.001)$ \\
\hline \multirow[t]{2}{*}{$\hat{P}(Z)$} & 2.618 \\
\hline & $(1.578)$ \\
\hline \multirow[t]{2}{*}{$\hat{P}(Z)^{2}$} & -3.073 \\
\hline & $(1.887)$ \\
\hline \multirow[t]{2}{*}{$\hat{P}(Z)^{3}$} & 4.813 \\
\hline & $(2.852)$ \\
\hline \multirow[t]{2}{*}{$\hat{P}(Z)^{4}$} & -3.228 \\
\hline & $(1.590)$ \\
\hline \multirow[t]{2}{*}{ Constant } & 6.702 \\
\hline & $(0.573)$ \\
\hline
\end{tabular}

Note: Standard errors in parenthesis. 
Table 15: Estimation Results for different LATEs

\begin{tabular}{|c|c|}
\hline Range of $U_{A}$ & LATE \\
\hline \multirow[t]{2}{*}{$0.003-0.040$} & 1.198 \\
\hline & $(0.035)$ \\
\hline \multirow[t]{2}{*}{$0.077-0.114$} & 1.216 \\
\hline & $(0.232)$ \\
\hline \multirow[t]{2}{*}{$0.151-0.188$} & 1.160 \\
\hline & $(0.143)$ \\
\hline \multirow{2}{*}{$0.225-0.262$} & 1.050 \\
\hline & $(0.082)$ \\
\hline \multirow[t]{2}{*}{$0.299-0.336$} & 0.917 \\
\hline & $(0.061)$ \\
\hline \multirow[t]{2}{*}{$0.374-0.411$} & 0.789 \\
\hline & $(0.081)$ \\
\hline \multirow[t]{2}{*}{$0.448-0.485$} & 0.681 \\
\hline & $(0.113)$ \\
\hline \multirow[t]{2}{*}{$0.522-0.559$} & 0.590 \\
\hline & $(0.149)$ \\
\hline \multirow[t]{2}{*}{$0.596-0.633$} & 0.477 \\
\hline & $(0.190)$ \\
\hline \multirow[t]{2}{*}{$0.670-0.707$} & 0.256 \\
\hline & $(0.244)$ \\
\hline \multirow[t]{2}{*}{$0.744-0.782$} & -0.179 \\
\hline & $(0.323)$ \\
\hline \multirow[t]{2}{*}{$0.819-0.856$} & -0.894 \\
\hline & $(0.444)$ \\
\hline \multirow[t]{2}{*}{$0.893-0.930$} & -1.863 \\
\hline & $(0.642)$ \\
\hline
\end{tabular}

Note: Standard errors are presented in parenthesis and were estimated with 1,000 bootstrap replications. 
Table 16: Test of Equality of LATEs

\begin{tabular}{rrr}
\hline \hline & Null Hypothesis & P-Value \\
\hline LATE $^{0.003-0.040}=$ LATE $^{0.077-0.114}$ & 0.895 \\
LATE $^{0.077-0.114}=$ LATE $^{0.151-0.188}$ & 0.586 \\
LATE $^{0.151-0.188}=$ LATE $^{0.225-0.262}$ & 0.153 \\
LATE $^{0.225-0.262}=$ LATE $^{0.299-0.336}$ & 0.029 \\
LATE $^{0.299-0.336}=$ LATE $^{0.374-0.411}$ & 0.012 \\
LATE $^{0.374-0.411}=$ LATE $^{0.448-0.485}$ & 0.023 \\
LATE $^{0.448-0.485}=$ LATE $^{0.522-0.559}$ & 0.067 \\
LATE $^{0.522-0.559}=$ LATE $^{0.596-0.633}$ & 0.055 \\
LATE $^{0.596-0.633}=$ LATE $^{0.670-0.707}$ & 0.008 \\
LATE $^{0.670-0.707}$ & $=$ LATE $^{0.744-0.782}$ & 0.000 \\
LATE $^{0.744-0.782}$ & $=$ LATE $^{0.819-0.856}$ & 0.000 \\
LATE $^{0.819-0.856}$ & $=$ LATE $^{0.893-0.930}$ & 0.000 \\
\hline & Joint Test & 0.000 \\
\hline \hline
\end{tabular}

Note: P-values were estimated with 1,000 bootstrap replications, following Carneiro, Heckman and Vytlacil (2011).

Table 17: Treatment Parameters

\begin{tabular}{rrr}
\hline \hline Treatment Parameter & Normal Model & Semiparametric Model \\
\hline ATE & 0.887 & 0.415 \\
TT & $(0.054)$ & $(0.129)$ \\
& 1.048 & 1.073 \\
TUT & $(0.066)$ & $(0.131)$ \\
& 0.809 & 0.107 \\
MPRTE $-P+\delta$ & $(0.066)$ & $(0.213)$ \\
& 0.956 & 0.929 \\
MPRTE $-P(1+\delta)$ & $(0.054)$ & $(0.068)$ \\
MPRTE $-Z^{k}+\delta$ & 0.916 & 0.809 \\
& $(0.055)$ & $(0.101)$ \\
& 0.937 & 0.884 \\
\hline \hline
\end{tabular}

Note: Standard errors are presented in parenthesis and were estimated with 1,000 bootstrap replications. 
Table 18: P-Values for different Hypothesis Tests

\begin{tabular}{rrr}
\hline \hline Hypothesis & Normal Model & Semiparametric Model \\
\hline$T T=M P R T E_{P+\delta}$ & 0.000 & 0.000 \\
$T T=M P R T E_{P(1+\delta)}$ & 0.000 & 0.001 \\
$T T=M P R T E_{Z^{k}+\delta}$ & 0.000 & 0.000 \\
\hline \hline
\end{tabular}

Note: Standard errors were estimated with 1,000 bootstrap replications.

Table 19: Treatment Parameters for Household Income Categories 1 and 2

\begin{tabular}{rrr}
\hline \hline Treatment Parameter & Normal Model & Semiparametric Model \\
\hline ATE & 0.646 & 0.139 \\
TT & $(0.053)$ & $(0.193)$ \\
& 0.757 & 0.845 \\
TUT & $(0.065)$ & $(0.156)$ \\
& 0.593 & -0.181 \\
MPRTE $-P+\delta$ & $(0.065)$ & $(0.300)$ \\
& 0.693 & 0.675 \\
MPRTE $-P(1+\delta)$ & $(0.053)$ & $(0.075)$ \\
MPRTE $-Z^{k}+\delta$ & 0.669 & 0.541 \\
& $(0.053)$ & $(0.106)$ \\
\hline \hline
\end{tabular}

Notas: The household income category 1 considers income levels ranging from $\$ 0$ to $\$ 278,000$ CLP and the household income category 2 from $\$ 278,000$ to $\$ 834,000$ CLP. Standard errors are presented in parenthesis and were estimated with 1,000 bootstrap replications. 
Table 20: Treatment Parameters for Household Income Category 3

\begin{tabular}{rrr}
\hline \hline Treatment Parameter & Normal Model & Semiparametric Model \\
\hline ATE & 1.118 & 0.839 \\
& $(0.054)$ & $(0.273)$ \\
TT & 1.090 & 1.377 \\
& $(0.193)$ & $(0.366)$ \\
TUT & 1.149 & 0.281 \\
& $(0.178)$ & $(0.488)$ \\
MPRTE $-P+\delta$ & 1.120 & 1.169 \\
& $(0.150)$ & $(0.195)$ \\
MPRTE $-P(1+\delta)$ & 1.127 & 1.042 \\
MPRTE $-Z^{k}+\delta$ & $(0.156)$ & $(0.274)$ \\
& 1.119 & 1.222 \\
\hline \hline
\end{tabular}

Notas: The household income category 3 considers income levels from $\$ 834,000$ CLP and on. Standard errors are presented in parenthesis and were estimated with 1,000 bootstrap replications.

Table 21: P-Values for different Hypothesis Tests (Household Income Categories 1 and 2)

\begin{tabular}{rrr}
\hline \hline Hypothesis & Normal Model & Semiparametric Model \\
\hline$T T=M P R T E_{P+\delta}$ & 0.000 & 0.000 \\
$T T=M P R T E_{P(1+\delta)}$ & 0.000 & 0.070 \\
$T T=M P R T E_{Z^{k}+\delta}$ & 0.000 & 0.002 \\
\hline \hline
\end{tabular}

Notas: The household income category 1 considers income levels ranging from $\$ 0$ to $\$ 278,000$ CLP and the household income category 2 from $\$ 278,000$ to $\$ 834,000$ CLP. Standard errors were estimated with 1,000 bootstrap replications.

Table 22: P-Values for different Hypothesis Tests (Household Income Category 3)

\begin{tabular}{rrr}
\hline \hline Hypothesis & Normal Model & Semiparametric Model \\
\hline$T T=M P R T E_{P+\delta}$ & 0.000 & 0.060 \\
$T T=M P R T E_{P(1+\delta)}$ & 0.000 & 0.207 \\
$T T=M P R T E_{Z^{k}+\delta}$ & 0.000 & 0.029 \\
\hline \hline
\end{tabular}

Notas: The household income category 3 considers income levels from $\$ 834,000$ CLP and on. Standard errors were estimated with 1,000 bootstrap replications. 
Figure 1: Total Undergraduate Enrollment

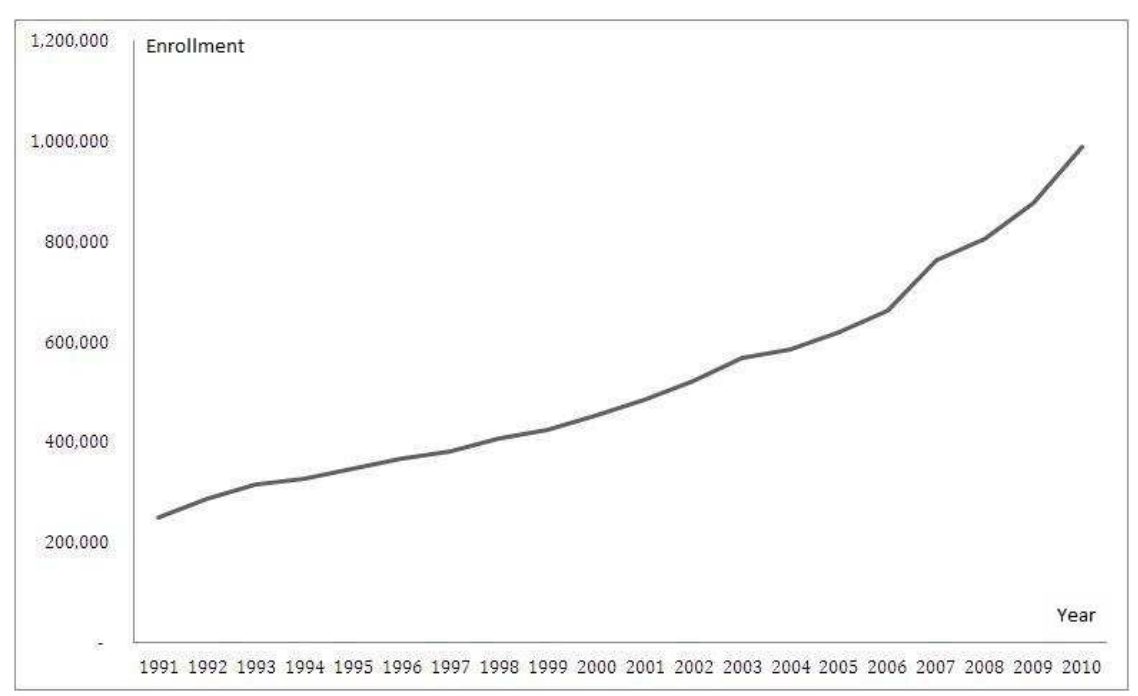

Source: Authors' elaboration based on information of the Chilean Ministry of Education.

Figure 2: Total Number of Financial Aids by Type

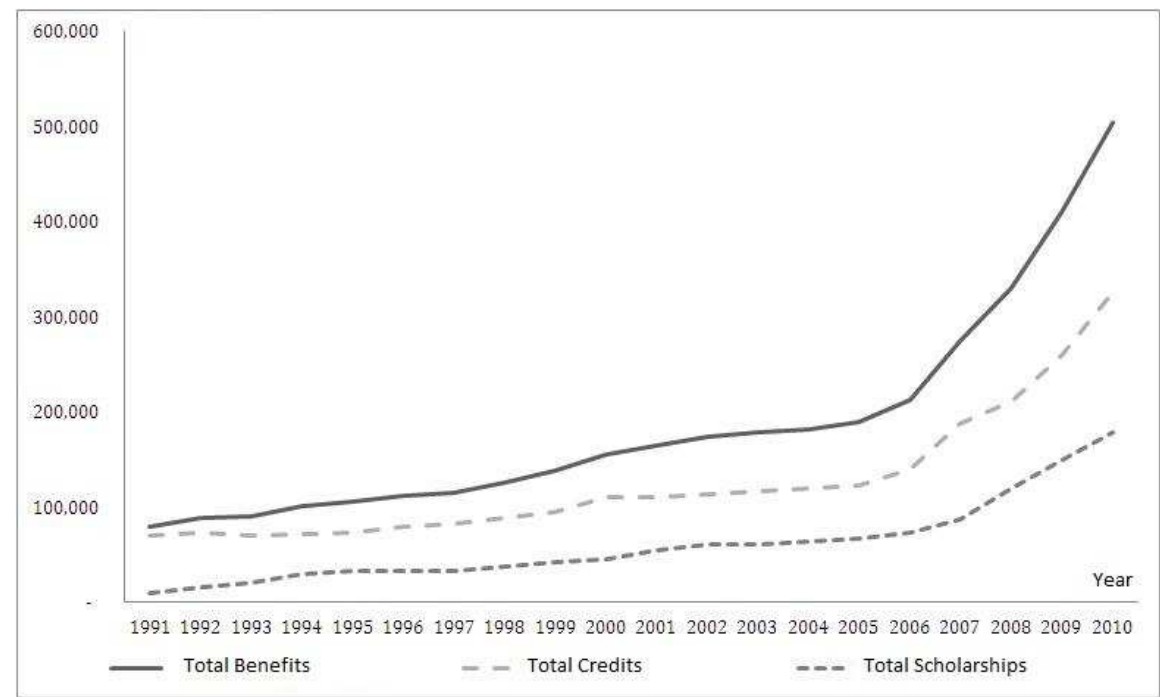

Source: Authors' elaboration based on information of the Chilean Ministry of Education. 
Figure 3: Distribution of the Propensity Score for Treated and Untreated

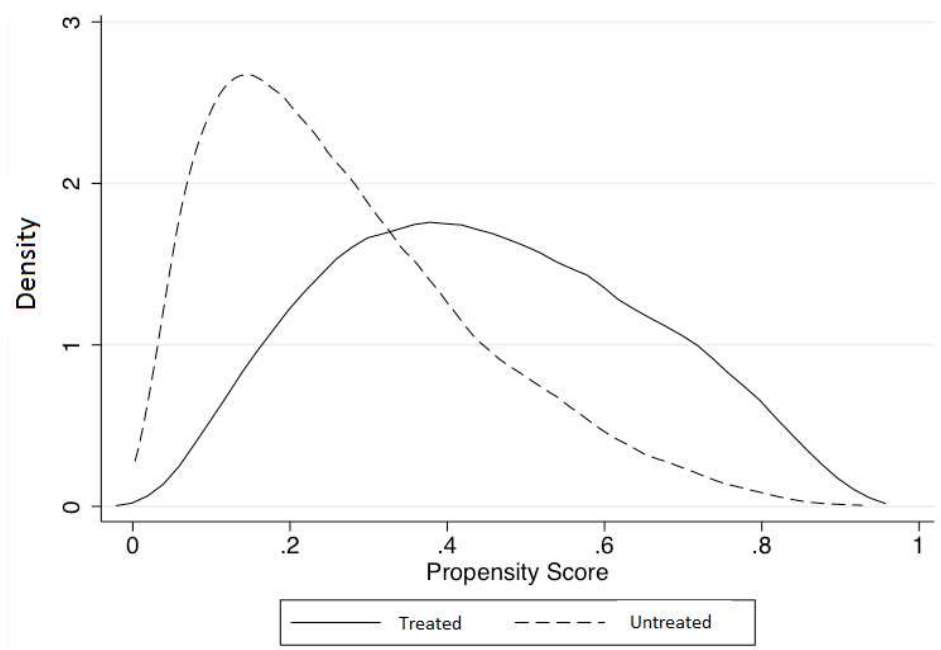

Source: Authors' elaboration.

Figure 4: Marginal Treatment Effect (Normal Model)

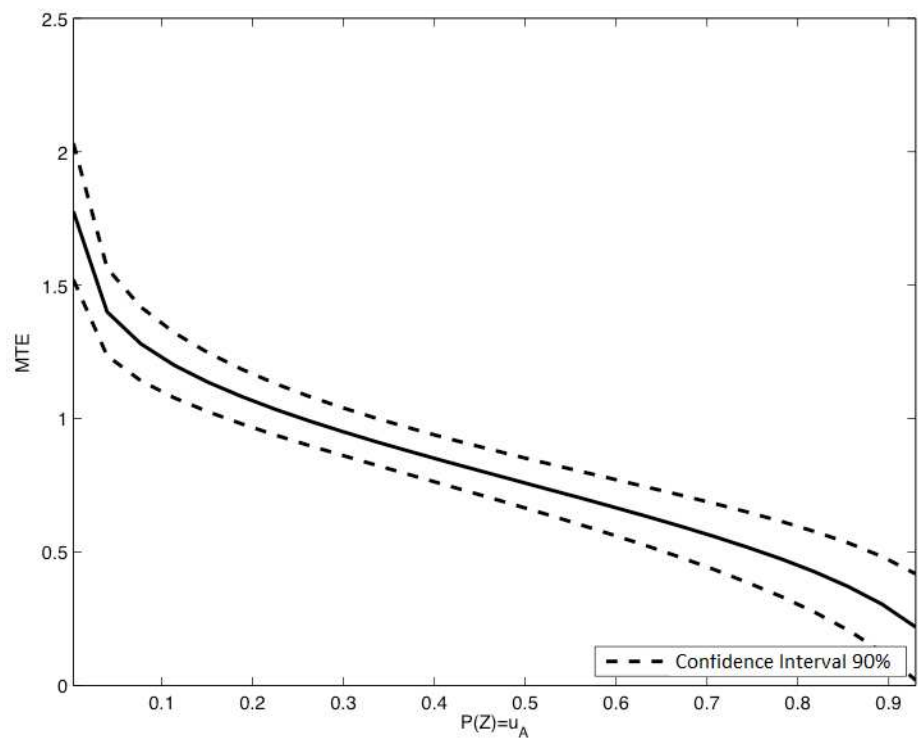

Source: Authors' elaboration. Note: Confidence intervals were calculated using 1,000 bootstrap replications. 
Figure 5: Marginal Treatment Effect (Semiparametric Model)

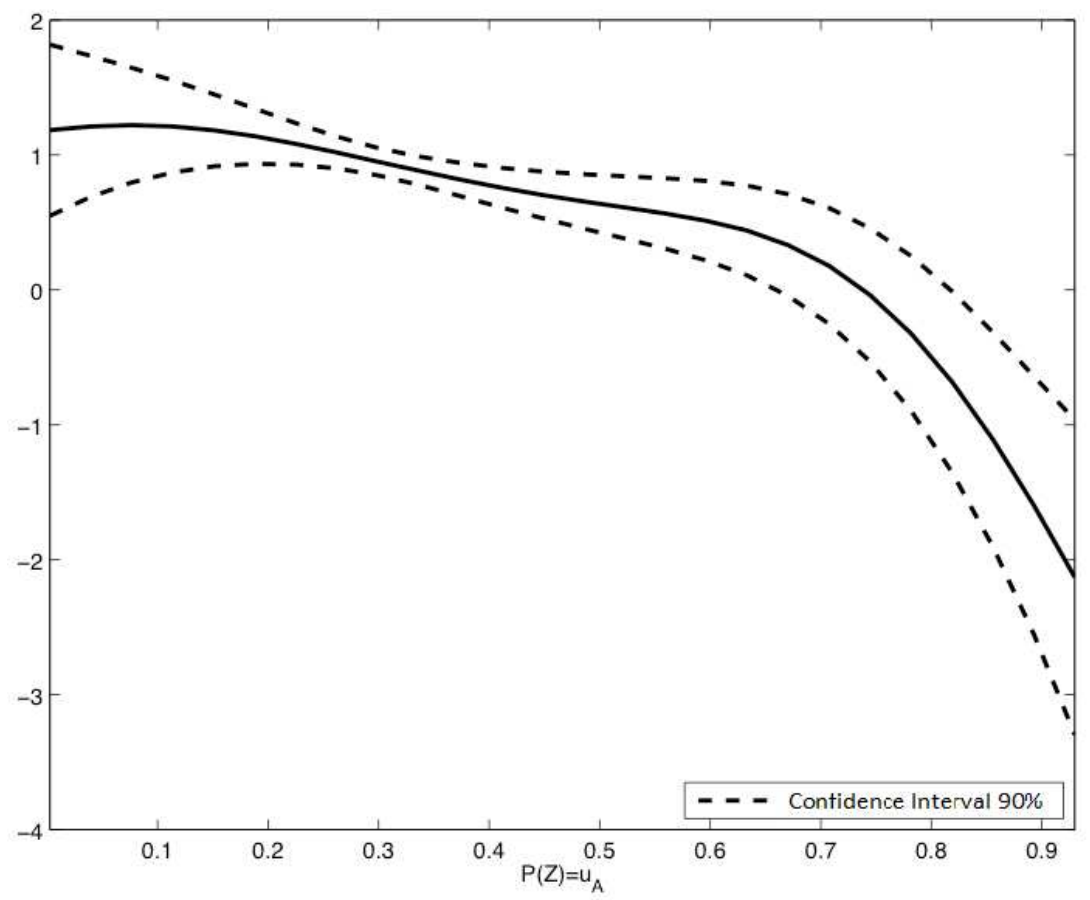

Source: Authors' elaboration. Note: Confidence intervals were calculated using 1,000 bootstrap replications. 
Figure 6: Conditional Probability Density Function

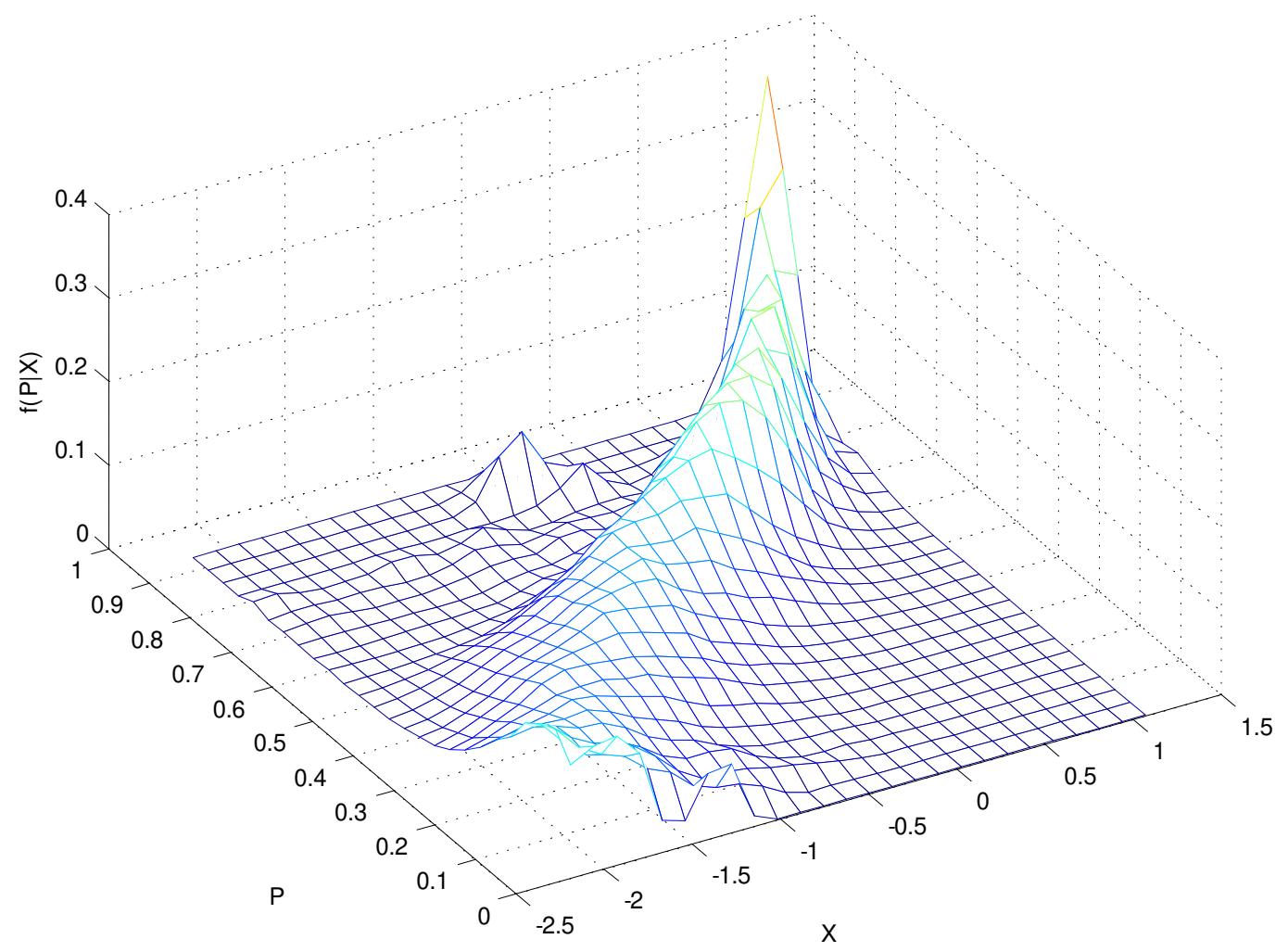

Source: Authors' elaboration. 
Figure 7: Conditional Probability Density Function for Household Income Categories 1 and 2

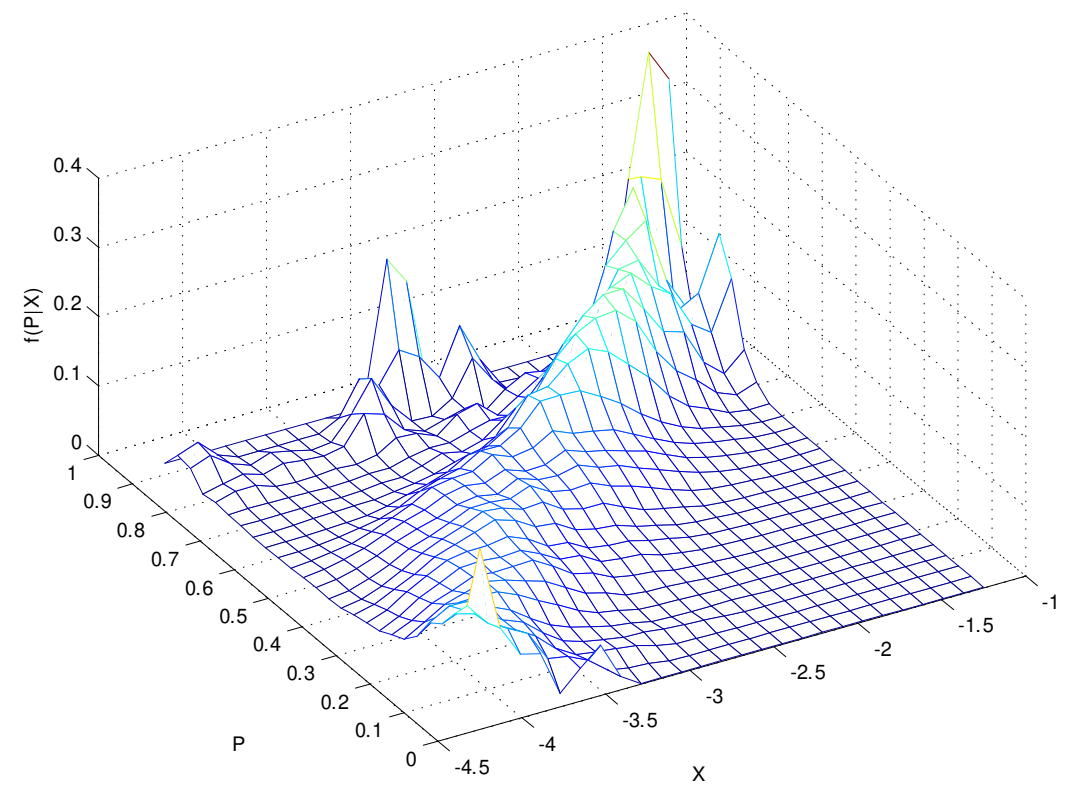

Source: Authors' elaboration. Note: The household income category 1 considers income levels ranging from $\$ 0$ to $\$ 278,000$ CLP and the household income category 2 from $\$ 278,000$ to $\$ 834,000$ CLP.

Figure 8: Conditional Probability Density Function for Household Income Category 3

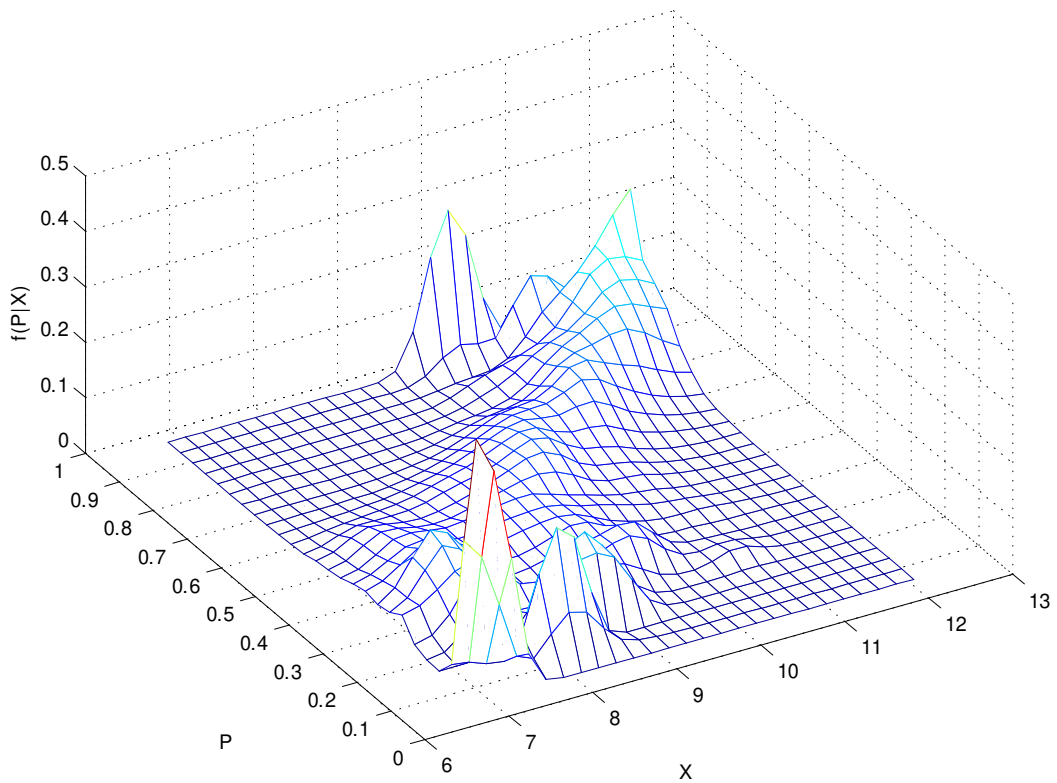

Source: Authors' elaboration. Note: The household income category 3 considers income levels from $\$ 834,000$ CLP and on. 
Figure 9: Marginal Treatment Effect for Household Income Categories 1 and 2 (Normal Model)

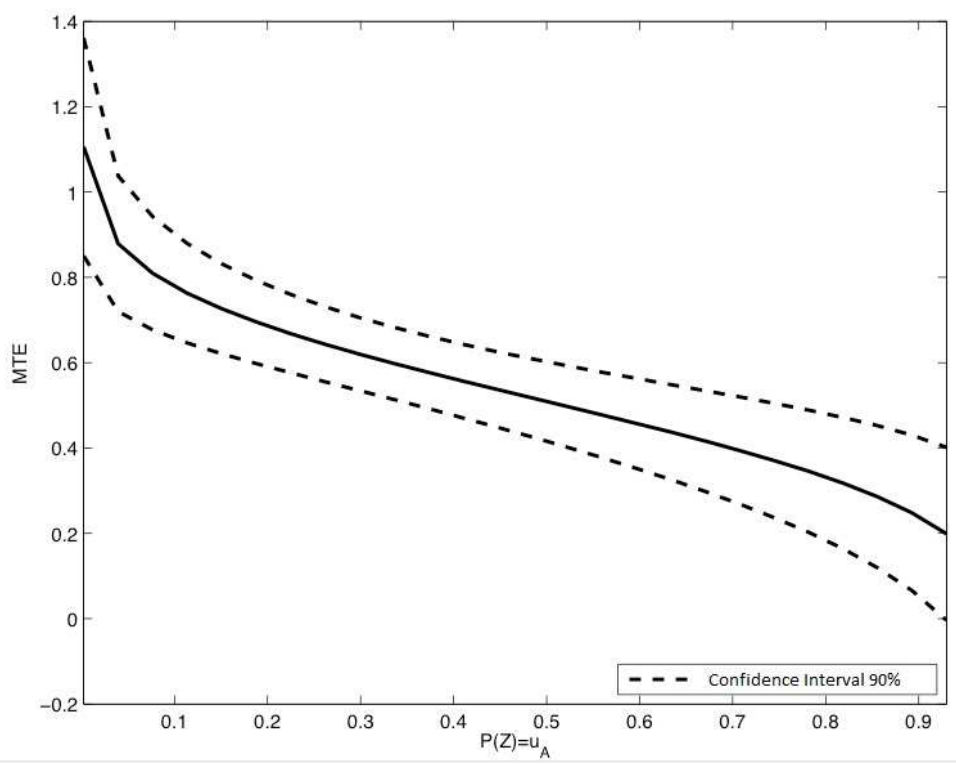

Source: Authors' elaboration. Note: The household income category 1 considers income levels ranging from $\$ 0$ to $\$ 278,000$ CLP and the household income category 2 from $\$ 278,000$ to $\$ 834,000$ CLP. The confidence intervals were estimtaed using 1,000 bootstrap replications.

Figure 10: Marginal Treatment Effect for Household Income Category 3 (Normal Model)

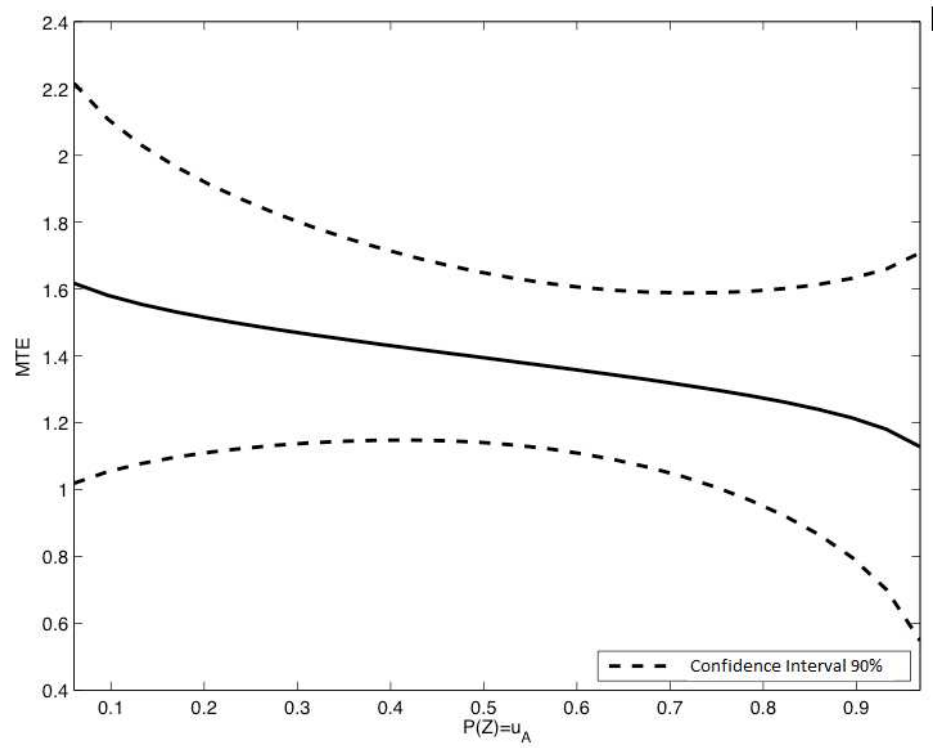

Source: Authors' elaboration. Note: The household income category 3 considers income levels from $\$ 834,000$ CLP and on. The confidence intervals were estimtaed using 1,000 bootstrap replications. 
Figure 11: Marginal Treatment Effect for Household Income Categories 1 and 2 (Semiparametric Model)

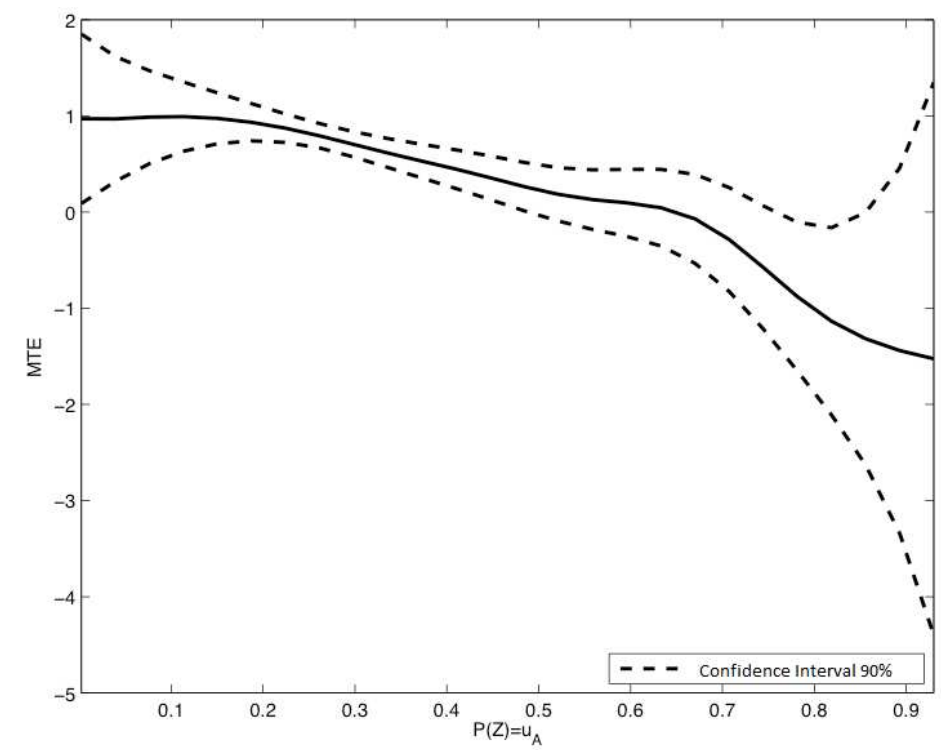

Source: Authors' elaboration. Note: The household income category 1 considers income levels ranging from $\$ 0$ to $\$ 278,000$ CLP and the household income category 2 from $\$ 278,000$ to $\$ 834,000$ CLP. The confidence intervals were estimtaed using 1,000 bootstrap replications.

Figure 12: Marginal Treatment Effect for Household Income Category 3 (Semiparametric Model)

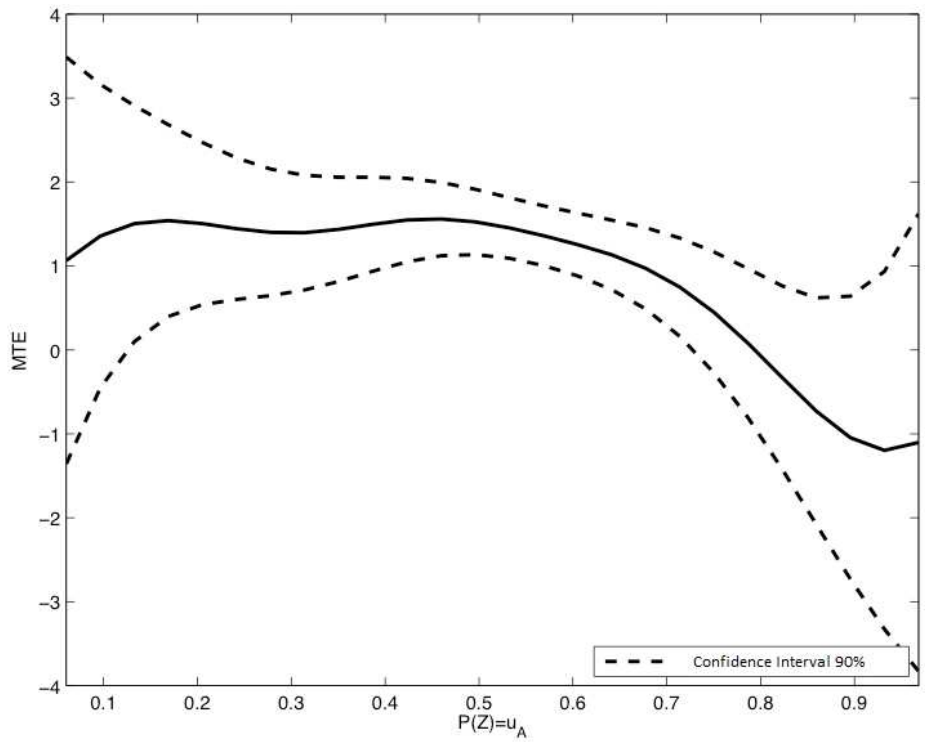

Source: Authors' elaboration. Note: The household income category 3 considers income levels from $\$ 834,000$ CLP and on. The confidence intervals were estimtaed using 1,000 bootstrap replications. 